\title{
JGR Oceans
}

\section{RESEARCH ARTICLE \\ 10.1029/2019JC015272 \\ Key Points: \\ - Mesoscale variability in the vertical OMZ boundaries is mostly characterized by a lens-shaped signature \\ - Intrathermocline eddies drive mesoscale variability in the upper oxycline of the coastal band and the CTZ north of $26^{\circ} \mathrm{S}$ \\ - Low-oxygen anomalies transported by ITEs contribute to defining the horizontal climatological boundary of the OMZ}

Correspondence to:

P. A. Auger,

pierreamael.auger@gmail.com

Citation:

Auger, P. A., Bento, J. P., Hormazabal, S., Morales, C. E., \& Bustamante, A. (2021). Mesoscale variability in the boundaries of the oxygen minimum zone in the eastern South Pacific: Influence of intrathermocline eddies. Journal of Geophysical Research: Oceans, 126, e2019JC015272. https:// doi.org/10.1029/2019JC015272

Received 7 MAY 2019

Accepted 23 NOV 2020
(C) 2020. American Geophysical Union. All Rights Reserved.
Mesoscale Variability in the Boundaries of the Oxygen Minimum Zone in the Eastern South Pacific: Influence of Intrathermocline Eddies

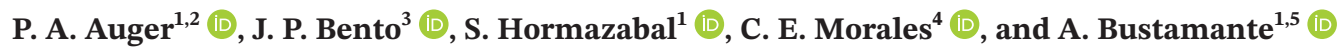 \\ ${ }^{1}$ Instituto Milenio de Oceanografía (IMO) and Escuela de Ciencias del Mar, Pontificia Universidad Católica de \\ Valparaíso, Valparaíso, Chile, ${ }^{2}$ Univ. Brest, CNRS (Centre National de la Recherche Scientifique), IRD (Institut de \\ Recherche pour le Développement), Ifremer, Laboratoire d'Océanographie Physique et Spatiale (LOPS), IUEM, Brest, \\ France, ${ }^{3}$ Escuela de Ciencias del Mar, Pontificia Universidad Católica de Valparaíso, Valparaíso, Chile, ${ }^{4}$ Instituto \\ Milenio de Oceanografía (IMO) and Departamento de Oceanografía, Facultad de Ciencias Naturales y Oceanográficas, \\ Universidad de Concepción, Concepción, Chile, ${ }^{5}$ División de Investigación Pesquera, Instituto de Fomento Pesquero \\ (IFOP), Valparaíso, Chile
}

Abstract The vertical variability in the oxygen minimum zone (OMZ) in the eastern South Pacific (ESP; $0-40^{\circ} \mathrm{S}$ ) is characterized by the influence of anticyclonic intrathermocline eddies (ITEs), which are subsurface-intensified mesoscale features that are frequently generated in the coastal upwelling zone off Peru and Chile. The unique lens-shaped signatures that ITEs leave on temperature, salinity, and dissolved oxygen vertical distributions are used as proxies to assess their influences on vertical OMZ boundaries and thickness. Data from in situ profiles in the region (World Ocean Database and Argo databases) are used in correlation analyses between anomalous depths (and vertical displacements) of oxyclines and isopycnals/isotherms, together with an objective eddy detection method based on satellite altimetry to identify the location of such profiles (i.e., outside or inside cyclonic and anticyclonic eddies). The results indicate that most of the vertical fluctuations in the climatological OMZ have a lens-shaped signature and that those at the mesoscale are largely due to ITEs. ITEs are a main driver of the upper oxycline variability in the coastal band, the coastal transition zone (CTZ, 3-10 ${ }^{\circ}$ from the coast) and beyond at mid-latitudes $\left(12-26^{\circ} \mathrm{S}\right)$. The influence of ITEs on the upper and lower oxycline variability is mostly observed within the horizontal (offshore) climatological boundary of the OMZ, suggesting that ITEs play a role in the OMZ offshore extension in the ESP. ITEs may produce mesoscale variations in the thickness of the surfaceoxygenated layer, resulting in potential changes in prey-predator interactions and in food web functioning.

Plain language summary The eastern South Pacific hosts one of the most intense zones of the world ocean where oxygen concentrations are extremely low, known as the oxygen minimum zones (OMZ), located at intermediate depths (from $100 \mathrm{~m}$ from the surface to a maximum of approximately $800 \mathrm{~m}$ depth). The vertical boundaries of this OMZ are influenced by a variety of physical processes; however, their specific contributions to total variability remain poorly known. This study focuses on the role of mesoscale intrathermocline eddies (ITEs), which produce a strong lens-shaped signal in the water column as they move from the coast to offshore, containing high-salinity and low-oxygen waters. The results show that ITEs drive most of the variability in the upper boundary of the OMZ, and, thus, they may influence the overall horizontal and vertical extension of the OMZ. The mesoscale variability of the thickness of the surface-oxygenated layer may structure marine food web functioning and carbon export, and global warming might amplify this impact if eddy activity increases and the OMZ shoals.

\section{Introduction}

Oxygen minimum zones (OMZs) are oxygen-deficient bodies of water that occupy large volumes of intermediate-depth waters in the eastern tropical and subtropical oceans (Helly \& Levin, 2004; Karstensen et al., 2008; Paulmier \& Ruiz-Pino, 2009; Stramma et al., 2010), including anoxic zones (Ulloa et al., 2012). A marked intensification, expansion, and shoaling of OMZs has been detected in recent decades (Bograd et al., 2008; Breitburg et al., 2018; Emerson et al., 2004; Stramma et al., 2008), although considerable uncertainty remains in distinguishing long-term trends from multidecadal cycles (Stramma et al., 2012). Under a 
global warming scenario, propositions or predictions have been made about an expansion of OMZs due to mechanisms involving changes in oxygen solubility, ventilation of the deep ocean, and/or biological oxygen consumption or respiration (see Couespel et al., 2019; Keeling et al., 2010; Matear \& Hirst, 2003; Oschlies et al., 2018; Schmidtko et al., 2017; Shaffer et al., 2009). The expansion may persist for at least several centuries even after atmospheric carbon dioxide stops rising (Yamamoto et al., 2015). Coarse-resolution Earth system climate models reproduce the global trend well but are unable to correctly reproduce regional changes in dissolved oxygen (DO) concentration (Cabré et al., 2015; Stramma et al., 2012). Indeed, their solutions are influenced mainly by the parameterization of biogeochemical processes and diapycnal mixing (Duteil \& Oschlies, 2011; Frenger et al., 2018), and by their capacity to resolve lateral eddy diffusion and mixing (Bahl et al., 2019; Gnanadesikan et al., 2012). Biogeochemical processes in OMZs are largely driven by microbial communities associated with anaerobic metabolism (e.g., denitrification, anammox), which are highly relevant in terms of fixed nitrogen loss, as well as its impact on primary production rate, carbon sequestration, and greenhouse gas production. Vertical movements in the upper limit of the OMZ (oxycline) are expected to alter such rates (Arévalo-Martínez et al., 2015; Jiao et al., 2014; Kalvelage et al., 2015), and also have a direct impact on most aerobic organisms through an expansion or contraction of their habitat within the upper mixed layer-seasonal thermocline, changes in their depth distribution within the OMZ or by alterations in their patterns of diel vertical migration (Bianchi et al., 2013; Gilly et al., 2013; Wishner et al., 2020).

The eastern South Pacific (ESP) region hosts one of the most productive coastal upwelling ecosystems in the world (Carr \& Kearns, 2003) and a relatively shallow and intense OMZ, the waters of which constitute the main source of coastal upwelling (Albert et al., 2010; Fuenzalida et al., 2009; Huyer et al., 1987; Morales et al., 1999). In this region, the OMZ is mostly associated with equatorial subsurface water (ESSW), which is distributed along the shelf and shelf break zones off Ecuador, Peru and Chile (Silva et al., 2009). This oxygen-depleted water mass (isopycnals $26.2-26.8 \mathrm{~kg} / \mathrm{m}^{3}$ ) is transported poleward from the equator along the continental slope by the Peru-Chile Undercurrent (PCUC) and as far south as $48^{\circ} \mathrm{S}$ (Silva \& Neshyba, 1979). The ESSW is continuously oxygenated by two other water masses along its pathway, including the subantarctic water (SAAW) from above and the Antarctic intermediate water (AIW) from below (Llanillo et al., 2013). The OMZ in the region has a tongue-like shape with the greatest vertical extent close to the coast and near the equator, narrowing poleward and toward the open ocean (Fuenzalida et al., 2009; Llanillo et al., 2018).

The vertical boundaries of this OMZ, but especially the upper oxycline, display a broad range of spatial and temporal scales of variation (Bertrand et al., 2011; Grados et al., 2016; Swartzman et al., 2008). The physical processes that are known to directly or indirectly (through biogeochemical processes) influence the vertical variability in the OMZ in this region include wind-induced coastal upwelling and Ekman pumping (Penven et al., 2005), large-scale circulation (PCUC; Pizarro-Koch et al., 2019; Silva et al., 2009), fine-scale to mesoscale processes (e.g., internal waves, fronts, filaments, eddies; Chaigneau et al., 2011; Grados et al., 2016; Hormazabal et al., 2013; Morales et al., 2012; Stramma et al., 2013; Vergara et al., 2016), and high frequency (gravity) and low-frequency (inertial) waves (Blanco et al., 2002; Echevin et al., 2014; Hormazabal et al., 2002; Huyer et al., 1987; Morales et al., 1999; Pizarro, 2002; Ramos et al., 2006, 2008).

Most of the physical processes involved in the vertical OMZ variability in the ESP produce a similar signature in the water column, which is also reflected in the distribution of isotherms/isopycnals. Such a signature involves a rise or depression of the seasonal and permanent pycnoclines (corresponding to the upper and lower oxyclines, respectively), producing a vertically coherent signature throughout the water column. In other cases, it involves a rise of the seasonal pycnocline and a depression of the main pycnocline, producing a lens-shaped signature in the water properties. In the case of physical processes restricted to the upper layer, such as surface eddies, only the seasonal pycnocline may be affected, leading to a more complex pattern of vertical variation in the OMZ; in the ESP, trapped fluid within cyclonic eddies have a typical vertical extent of $240 \mathrm{~m}$ compared to $530 \mathrm{~m}$ in anticyclonic eddies (Chaigneau et al., 2011). In addition, biological processes can lead to deviations in the oxycline fluctuations from those of isopycnals in regions of low-oxygen waters. This includes DO production from subsurface photosynthesis at or near the upper oxycline (Garcia-Robledo et al., 2017; Vergara et al., 2016) and DO consumption from respiration by vertical migration toward the upper oxycline (Bianchi et al., 2013). Overall, the scarcity of observational time series 
in the ESP has been a difficulty in the evaluation of the individual impact of the different processes involved in vertical OMZ variability. To the best of our knowledge, no attempt has been made to assess the extent to which these mechanisms drive the vertical OMZ variability in the ESP based on in situ time series.

For the most part, the vertically coherent fluctuations in the seasonal and permanent pycnoclines off Peru and Chile have been attributed to surface mesoscale eddies (Morales et al., 2012; Stramma et al., 2013), seasonal wind-induced Ekman pumping (Penven et al., 2005; Ramos et al., 2006), and interannual low-frequency coastal-trapped waves (Kelvin waves; Blanco et al., 2002; Huyer et al., 1987; Morales et al., 1999; Ramos et al., 2006), which then radiate offshore as Rossby waves (Ramos et al., 2006). The vertical displacements of isopycnals produced by those processes can reach $\sim 250 \mathrm{~m}$ (see references above), whereas coastal upwelling and intraseasonal/seasonal low-frequency waves seem to generate smaller displacements (30-50 m; Echevin et al., 2014; Ramos et al., 2006).

Lens-shaped fluctuations in the isopycnals in the ESP can result from variability in the PCUC, i.e., meandering and fluctuations in its poleward expansion (Pizarro-Koch et al., 2019), high-order baroclinic modes associated with low-frequency Rossby waves forced at the equator (Ramos et al., 2006, 2008), and/ or subsurface-intensified (intrathermocline) anticyclonic eddies (ITEs) (Johnson \& McTaggart, 2010). In this region, ITEs are common features characterized by low-oxygen $(\leq 1 \mathrm{ml} / \mathrm{L}$, equivalent to $44.6 \mu \mathrm{mol} / \mathrm{kg}$ ), high-salinity (34.2-34.6) water lenses at the subsurface level (100-400 m depth) due to their near coastal formation associated with PCUC instabilities and the associated ESSW (Contreras et al., 2019; Czeschel et al., 2015; Hormazabal et al., 2013; Morales et al., 2012; Stramma et al., 2014, 2013; Thomsen et al., 2016). In contrast with the other lens-shaped processes mentioned above, ITEs in the ESP contribute to the transport of significant volumes of water and biogeochemical tracers from the coastal upwelling area toward the subtropical South Pacific gyre (Combes et al., 2015; Frenger et al., 2018; Johnson \& McTaggart, 2010). The vertical displacements of the isopycnals observed in ITEs can reach $50 \mathrm{~m}$ in the seasonal pycnocline (upper oxycline) and $250 \mathrm{~m}$ in the permanent pycnocline (lower oxycline). The seasonal fluctuation in the poleward expansion of the PCUC may compete with ITEs located near the coast in terms of driving vertical displacements of the seasonal pycnocline, but this mechanism is unlikely for the permanent pycnocline (Pizarro-Koch et al., 2019). High-order baroclinic modes of low-frequency Rossby waves have been reported to generate relatively smaller displacements at the semiannual $(\sim 10 \mathrm{~m}$, concentrated near the surface above 100 m depth; Ramos et al., 2006) and interannual ( 30 m; Ramos et al., 2008) scales. Owing to the relatively strong vertical displacements ITEs produce locally, they might play a significant role in the vertical OMZ variability.

In this study, we took advantage of the lens-shape signature in the water column properties and the surface expression in the sea surface height of ITEs to identify their effect on the vertical variability in the OMZ boundaries in the ESP. In situ profiles of temperature, salinity, and DO concentration within the OMZ region and correlation analyses between anomalous vertical displacements of oxyclines and isopycnals/isotherms were used to obtain a spatial characterization of the influence of ITEs. This analysis was conducted in combination with the application of an objective eddy detection method based on satellite altimetry to identify whether such profiles were located outside or within eddies and to distinguish between profiles in cyclonic eddies (CEs) and anticyclonic eddies (AEs). In this study, the emphasis was placed on the upper oxycline because of its relevance in terms of biogeochemical cycling within the OMZ and habitat compression for a great proportion of marine life other than microbes.

\section{Data and Methods}

\subsection{World Ocean Database (WOD2013) and Argo Profiles}

In situ ocean vertical profiles of temperature, salinity and DO concentration over the 1928-2016 period were obtained for the ESP region from three different sources, including the World Ocean Database 2013 (19282013, WOD2013; Boyer et al., 2013; http://www.nodc.noaa.gov/OC5/WOD13), the International Argo Program (2000-2016; Argo, 2000; downloaded from http://www.argo.ucsd.edu on 23 February 2018), and Argo profiles available from the Chilean community (O. Ulloa, pers. com.). The WOD2013 database is a compilation of profiles from ocean stations (OSD), some profiling floats not present in the Argo database (PFL), and 

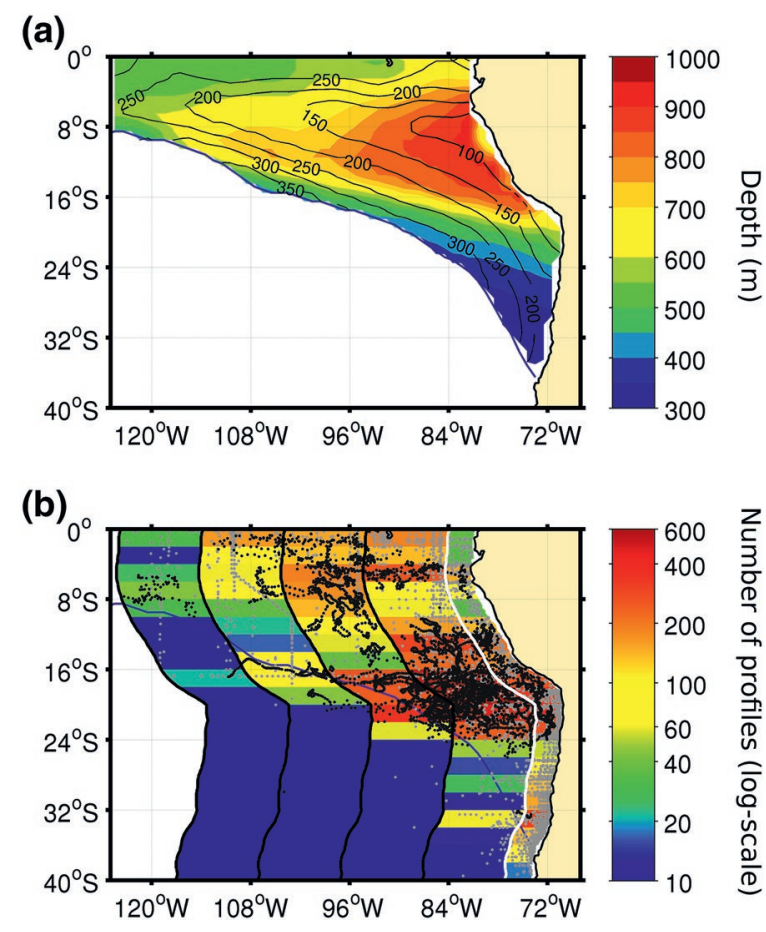

Figure 1. Climatological (time-mean) depth distribution of the upper (contours) and lower (background color) oxycline in the ESP from the World Ocean Atlas 2013 (WOA 2013) product (a) and distribution of WOD2013 (gray dots) and Argo (black dots) CTD-O profiles in the ESP where low-oxygen waters were detected (b). In b, the spatial subdomains used to aggregate profiles are superimposed (see Section 2.4), and the background color code represents the number of profiles in each subdomain that were available for the analysis. In both figures, the blue line indicates the horizontal or offshore climatological boundary of the OMZ (DO: $1 \mathrm{ml} / \mathrm{L}$ ). CTD-O, conductivity-temperature-depth-oxygen; DO, dissolved oxygen; ESP, eastern South Pacific; OMZ, oxygen minimum zone; WOD, World Ocean Database.
CTD-O data (conductivity-temperature-depth-oxygen) obtained from several oceanographic cruises focused on the characterization of water mass distributions from the mesoscale to regional-basin scales (Boyer et al., 2013). Data obtained from free-drifting profiling floats (Argo type) have already allowed the characterization of mesoscale processes, such as subsurface eddies (Chaigneau et al., 2011; Johnson \& McTaggart, 2010; Pegliasco et al., 2015), and their nearly random sampling procedure is particularly suitable for the purposes of the present study. To avoid sampling uncertainties, only quality-controlled data were considered in this study ("accepted values" and "good data" from the WOD2013 and Argo datasets, respectively; see documentations at https://data.nodc.noaa.gov/ woa/WOD13/DOC/wod13readme.pdf and https://argo.ucsd.edu/data/ how-to-use-argo-files). Additional postprocessing was applied to profiles presenting some noisy signals within the upper and/or lower oxycline.

A total of 9,506 profiles ( $28 \%$ of the total profiles available) were detected to show a well-defined OMZ (DO $\leq 1 \mathrm{ml} / \mathrm{L}$ ) located between the surface and deep oxygenated water masses in the study region (Figure 1). For each profile, the depth of isopycnals in the $25.5-27.5 \mathrm{~kg} / \mathrm{m}^{3}$ range (with steps of $0.1 \mathrm{k} / \mathrm{m}^{3}$ ) and the depth of isotherms in the $3-23^{\circ} \mathrm{C}$ range (with steps of $1^{\circ} \mathrm{C}$ ) was calculated. These ranges correspond to hydrographic properties observed in the ESSW water mass associated with the OMZ in the ESP (Hormazabal et al., 2013; Morales et al., 2012; Silva et al., 2009; Stramma et al., 2013). The depths of the upper and lower oxyclines were determined by identifying the boundaries of the depth range with DO concentrations $\leq 1 \mathrm{ml} / \mathrm{L}$. However, it was first verified that from surface to bottom, DO decreased (increased) through the upper (lower) oxycline. When DO crossed the $1 \mathrm{ml} / \mathrm{L}$ threshold more than two times over a profile (i.e., more than one upper or lower oxycline was found), a gradual smoothing was applied until it was crossed only twice. In these cases ( $\sim 22 \%$ of the profiles within the OMZ), identical smoothing was applied to the temperature and density profiles for data coherence. Then, the OMZ thickness was estimated. The selection of the $1 \mathrm{ml} / \mathrm{L}$ threshold was based on the following elements: (a) it is consistent with physiological data, indicating that a DO concentration range of $60-120 \mu \mathrm{mol} / \mathrm{kg}$ ( 1.35-2.7 ml/L) was already seriously hypoxic for many marine organisms (Ekau et al., 2010), (b) it was previously considered for OMZ studies in the ESP (Fuenzalida et al., 2009; Hidalgo et al., 2005; Morales et al., 1999), and (c) it is consistent with the levels of DO observed in the core of ITEs off Chile (Hormazabal et al., 2013; Morales et al., 2012) and Peru (Stramma et al., 2013; Thomsen et al., 2016).

\subsection{Satellite Data and Eddy Tracking}

Satellite altimetry data over the 1993-2016 period were obtained from the Pujol et al., 2016 product (Pujol et al., 2016; http://www.aviso.altimetry.fr). This product accurately represents the mesoscale activity in coastal regions of eastern boundary upwelling systems, where mesoscale features have been proven to play a crucial role in the export of coastal water masses toward the open ocean (Capet et al., 2014). These data were used to identify the presence of mesoscale eddies and to identify when a given in situ profile was located outside or inside a cyclonic eddy (CE) or an anticyclonic eddy (AE).

Objective eddy detection was carried out using the "py-eddytracker" procedure (http://imedea.uib-csic.es/ users/emason/py-eddytracker) based on the detection of closed contours in sea level anomalies (Mason et al., 2014) from satellite altimetry data. Before running the eddy detection algorithm, daily fields of sea level anomalies were spatially high-pass filtered by removing a smooth field obtained from a Gaussian filter 
with a zonal (meridional) major (minor) radius of $10^{\circ}\left(5^{\circ}\right)$. Contours of sea level anomalies were computed at $0.2 \mathrm{~cm}$ intervals for levels $-100-100 \mathrm{~cm}$, and closed contours were searched from $100(-100) \mathrm{cm}$ downward (upward) to identify cyclones (anticyclones). To be selected as the effective perimeter of an eddy, an identified closed contour must meet a series of criteria related to amplitude $(1-150 \mathrm{~cm})$, radius $\left(0.35-4.46^{\circ}\right)$, and number of local extrema (limited to 1). To maximize eddy detection along individual sections, we did not filter out highly irregular closed contours. Indeed, the weak surface signal of ITEs makes it challenging to detect their presence in altimetry satellite data (Assassi et al., 2016; Stramma et al., 2014).

\subsection{Detection of Lens-Shape versus Vertically Coherent Signature in Hydrographic Profiles}

Climatological (time-mean) hydrographic profiles from the World Ocean Atlas (WOA 2013; Locarnini et al., 2013; Zweng et al., 2013; Garcia et al., 2014) were used to calculate anomalies of the depth of isopycnals, isotherms, upper and lower oxyclines, as well as of OMZ thickness for each CTD-O and Argo profile (see Section 2.1). To do so, the WOA 2013 values were spatially interpolated at the longitude/latitude position of each profile. Anomalies were then estimated by substracting the climatological average from data in each profile.

The lens-shaped signature, known to characterize ITEs (McGillicuddy, 2016), was distinguished from the signature of processes producing vertically coherent displacements of isopycnals by linear correlation analyses based on a conceptual scheme of the patterns of vertical variability in the OMZ boundaries (Figure 2). Pearson's correlations were performed between subsets of data (see Section 2.4) of the anomalous depth (and vertical displacements) of isopycnals in the $25.5-27.5 \mathrm{~kg} / \mathrm{m}^{3}$ range (and isotherms in the $3-23^{\circ} \mathrm{C}$ range) and of the vertical OMZ boundaries, including the upper and lower oxycline and its thickness (or rate of expansion). The statistical significance was tested using the t-test.

For a given subset of profiles, correlation coefficients were computed as follows:

$$
R^{\operatorname{ISOPYCNAL}(i)}=\frac{\sum_{p=1}^{n}\left(Z_{p}^{\mathrm{OMZ}}-\overline{Z^{\mathrm{OMZ}}}\right) \cdot\left(Z_{p}^{\operatorname{ISOPYCNAL}(i)}-\overline{Z^{\operatorname{ISOPYCNAL}(i)}}\right)}{\sqrt{\sum_{p=1}^{n}\left(Z_{p}^{\mathrm{OMZ}}-\overline{Z^{\mathrm{OMZ}}}\right)^{2}} \sqrt{\sum_{p=1}^{n}\left(Z_{p}^{\operatorname{ISOPYCNAL}(i)}-\overline{Z^{\operatorname{ISOPYCNAL}(i)}}\right)^{2}}}
$$

where $p$ represents profiles, $n$ is the number of profiles in the subset (i.e., sample size; $n-1$ when we consider displacement), $Z_{p}^{\mathrm{OMZ}}$ is the $p$ th sample of anomalous depth (or vertical displacement) of the upper or lower oxycline, or the sample of OMZ thickness (or rate of vertical expansion), $Z_{p}^{\operatorname{ISOPYCNAL}(i)}$ is the $p$ th sample of depth (or vertical displacement) of the $i$ th isopycnal (ISOPYCNAL $(i)=0.1 \cdot(i-1)+25.5 \mathrm{~kg} / \mathrm{m}^{3}$, where $i=1-21$ ), and $\overline{Z^{\mathrm{OMZ}}}$ and $\overline{Z^{\mathrm{ISOPYCNAL}(i)}}$ are the average over the $\mathrm{n}$ profiles. The same procedure was applied for the isotherms (ISOTHERM $(i)=\mathrm{i}+2^{\circ} \mathrm{C}$, where $i=1-21$ ).

Basically, a dominant signature of lens-shaped processes in the upper oxycline is identified when anomalous vertical displacements in the upper oxycline correlate negatively with those in the lower isopycnals/ isotherms, and positively with those in the upper isopycnals/isotherms. The same applies for the lower oxycline when its anomalous vertical displacements correlate negatively with those in the upper isopycnals/isotherms, and positively with those in the lower isopycnals/isotherms (Figure 2a). The local vertical expansion and contraction of the OMZ is reflected in a positive (negative) correlation between the rate of expansion of the $\mathrm{OMZ}$ and vertical displacements in the lower (upper) isopycnals/isotherms. In contrast, the $\mathrm{OMZ}$ experiences mostly vertically coherent displacements when vertical displacements in the upper and lower oxyclines correlate positively with those in isopycnals/isotherms over the whole water column (Figure 2b), as it is expected in surface cyclonic and anticyclonic eddies for instance. In this case, the OMZ thickness may remain unaltered, or its variations may correlate positively with vertical displacements in isopycnals/isotherms in the water column owing to the limitation of the upward position of the upper oxycline by the surface mixed layer ventilation. In the case of surface eddies, the patterns of OMZ vertical variability may represent a mixture of these two patterns if the lower oxycline (permanent pycnocline) is located below 


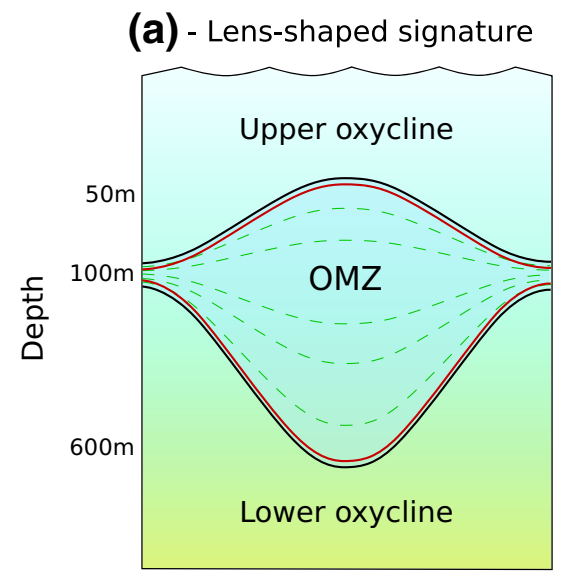

(b) - Vertically coherent signature
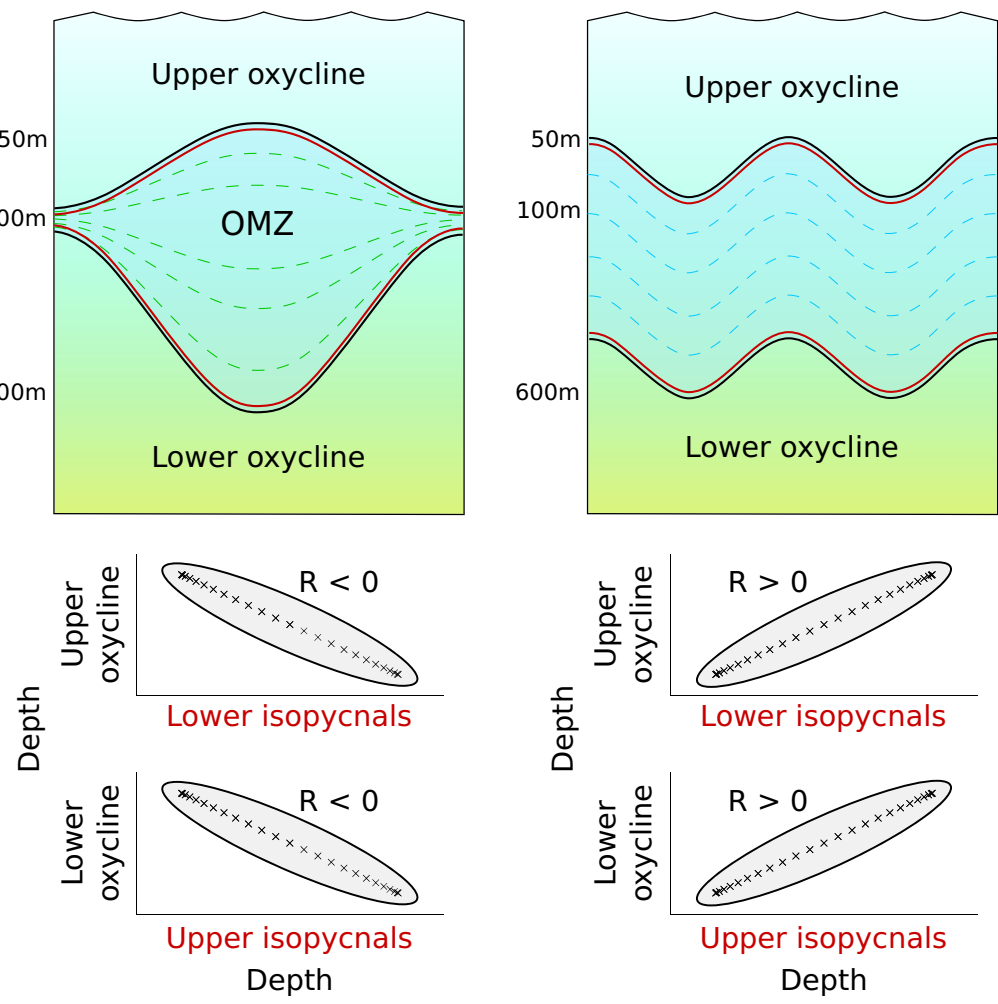

Figure 2. Conceptual scheme of the patterns of vertical variability in the OMZ boundaries (light blue color in top panels) and the associated data dispersion diagrams and expected correlations between the oxycline and isopycnal depths (central and bottom panels) due to processes producing displacements with (a) lens-shaped or (b) vertically coherent signatures. Top panels: black (red) lines are the upper and lower oxyclines (isopycnals/isotherms), and dotted lines represent the perturbations of isopycnals/isotherms following the lens-shaped (green) and vertically coherent (blue) signatures; depth references are indicative and correspond to observations of the OMZ in the ESP. Central (bottom) panels: depth of the upper (lower) oxycline versus the depth of the lower (upper) isopycnals/isotherms for each case and the corresponding sign of the significant correlation coefficients (R); black crosses represent the isolines (theoretical sinusoids) and gray areas are indicative of a more realistic dispersion. Note that in the lens-shaped case, $R$ values will be positive between the depth of the upper (lower) oxycline and that of the upper (lower) isopycnals. ESP, eastern South Pacific; OMZ, oxygen minimum zone.

the depth range occupied by a surface eddy, so that a lens-shaped signature can be only identified in the upper oxycline (seasonal pycnocline).

\subsection{Spatial Characterization of the Vertical Variability in the OMZ Boundaries}

To characterize the spatial pattern of vertical OMZ variability, the selected profiles were first sorted into five arbitrary meridional bands extending from $0^{\circ}$ to $40^{\circ} \mathrm{S}$ (Figure 1). The coastal band was defined by the subdomain extending from the $500 \mathrm{~m}$ isobath to $3^{\circ}$ offshore to exclude the continental shelf, the adjacent band defined the coastal transition zone $\left(\mathrm{CTZ}: 3-10^{\circ}\right)$, and three further offshore bands were considered $\left(10-20^{\circ}, 20-30^{\circ}\right.$, and $30-40^{\circ}$ offshore of the $500 \mathrm{~m}$ isobath). The profiles were subsequently aggregated into $2^{\circ}$ latitude bins.

Correlation analyses of depth anomalies or vertical displacements were performed separately in each of the subdomains defined above, considering three types of datasets (each one with at least six profiles). First, the pool of depth anomalies of oxyclines and isopycnals/isotherms available in each subdomain over the 19282016 period were analyzed, without accounting for the spatiotemporal coherence between them. Second, the analyses were focused on the vertical displacements between those profiles displaying spatiotemporal 
coherence to resolve the mesoscale field in each subdomain. Third, the same procedure was repeated along individual sections that resolved the mesoscale in each subdomain.

In the last two types, the collocation of each CTD-O and Argo profile with satellite altimetry data over the 1993-2016 period and objective eddy detection (see Section 2.2) made it possible to identify whether a profile was located outside or inside an eddy. Then, the correlation analyses were repeated in each subdomain for each subset of vertical displacements outside eddies, inside CEs and inside AEs.

Two profiles were considered to resolve the mesoscale field if the "horizontal distance" and "time-lapse" between them did not exceed certain thresholds with regard to the average distance between two stations for sampling the same eddy (i.e., eddy diameter) and to the average duration, as a fixed station can be affected by a passing eddy given its size and westward propagation speed (i.e., eddy diameter divided by propagation speed). Eddies are larger and move faster at lower latitudes such that thresholds, horizontal distances and time-lapses depend on latitude, with two different regimes detected north and south of $10^{\circ} \mathrm{S}$ (Chaigneau et al., 2009). Based on this pattern (see Figure 1d in Chaigneau et al., 2009), we established linear regressions between both thresholds and latitude (positive in the Southern Hemisphere) for the two regimes:

$$
\begin{gathered}
\text { South of } 10^{\circ} \mathrm{S} \text { : Horizontal distance }(\mathrm{km})=-4,3333 \times \text { Latitude }\left({ }^{\circ} \mathrm{S}\right)+303,3333 \\
\text { Timelapse }(d)=1,6142 \times \operatorname{Latitude}\left({ }^{\circ} S\right)+35,7422 \\
\text { North of } 10^{\circ} \mathrm{S} \text { : Horizontal distance }(\mathrm{km})=-12 \times \operatorname{Latitude}\left({ }^{\circ} \mathrm{S}\right)+380 \\
\text { Timelapse }(d)=3,518 \times \text { Latitude }\left({ }^{\circ} S\right)+16,7033
\end{gathered}
$$

\section{Results}

\subsection{Examples of the Impact of the ITE Signature on Vertical OMZ Variability}

A visual analysis of individual sections of CTD-O profiles provides examples of the lens-shaped signature represented in Figure 2a. The influence of ITEs on producing such a shape is supported by concurrent observations of anticyclonic swirls in the satellite altimetry data.

First, the imprint of ITEs inside the OMZ (Figure 3) is exemplified by a section sampled at $20-22^{\circ} \mathrm{S}$ and 200-300 km from the coast $\left(71-74^{\circ} \mathrm{W}\right)$. Over a 3-month period in 2008, three occurrences of the lens-shaped signature associated with ITEs were recorded along the section. Simultaneous elevations (depressions) of the upper (lower) isotherms, isopycnals and oxycline are clearly detected from April 8th to 26, 2008, May 5 to 14, 2008, and May 29 to July 1, 2008 and were associated with a marked high-salinity subsurface anomaly (Figures 3a-3d). Satellite altimetry reveals that the same ITE seems to have been sampled during these three instances (Figures 3g, 3h, 3j, and 3l-3o). Other profiles sampled over the edge of surrounding CEs and vertical movements due to these structures were rather vertically coherent (Figures 3a, 3c, and 3d). The impact of ITEs overwhelmed the effect of these processes over the whole section, as attested by the lens-shaped signature in the correlation patterns obtained between the depth of oxyclines and isopycnals/ isotherms (Figure 3p).

Second, a section sampled $400-600 \mathrm{~km}$ away from the coast $\left(24-26^{\circ} \mathrm{S}, 74-78^{\circ} \mathrm{W}\right)$ over a 10 -month period in 2012-2013 (Figure 4) provides an example of ITE imprints on the horizontal borders of the OMZ off northern Chile. Three ITEs were sampled along this section. The first profiles were sampled in the region between two ITEs, which were later sampled at their centers around May 27 and from July 26 to August 5, 2012 (Figures 4e-4h). In waters between these ITEs, the high-salinity subsurface anomaly was lost (Figure $4 \mathrm{~b}$ ), and the OMZ became thinner due to a simultaneous deepening (shoaling) of the upper (lower) oxycline (Figure 4d). The second ITE was sampled at its center from July 26, to August 5, 2012 (Figure 4h) and later from September 4, to October 4, 2012 (Figure 4j). The OMZ became thinner from October 4, to December 3, 2012 when profiles were sampled outside an AE (Figure 4k). Then, a third ITE hosting a thick 

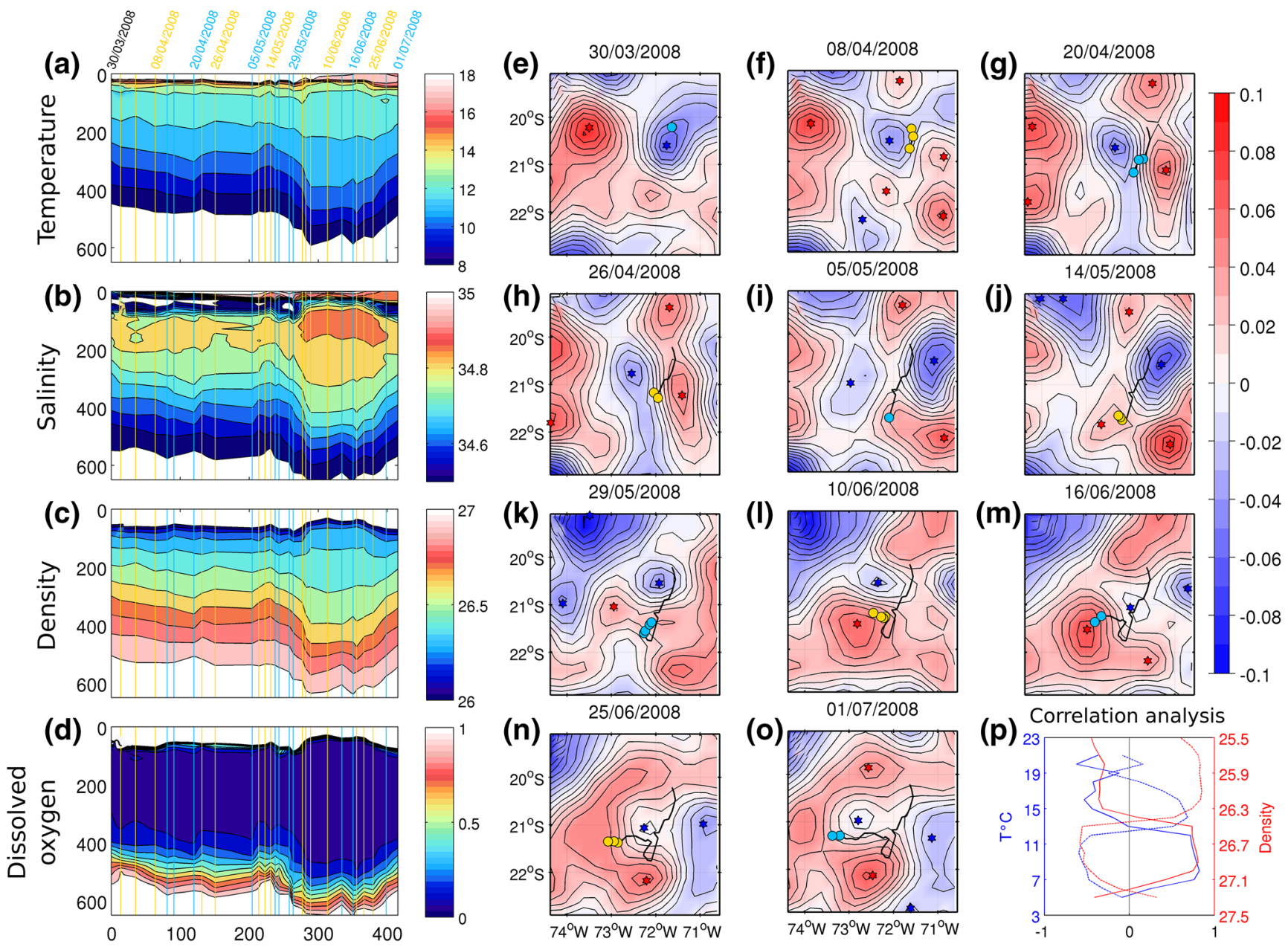

Figure 3. Vertical sections of (a) temperature $\left({ }^{\circ} \mathrm{C}\right)$, (b) salinity, (c) density $\left(\mathrm{kg} / \mathrm{m}^{3}\right)$, and (d) DO $(\mathrm{ml} / \mathrm{L})$ as a function of the accumulated distance between consecutive profiles ( $x$-axis) from the "CL001072" profiling float in the PFL data set (March 30 to July 1, 2008, WOD2013), together with selected snapshots (eo) of sea level anomalies (Pujol et al., 2016) within the time period of the section. Temperature, density and DO values out of the ranges 3-23 ${ }^{\circ} \mathrm{C}, 25.5-27.5 \mathrm{~kg} /$ $\mathrm{m}^{3}$, and $0-1 \mathrm{ml} / \mathrm{L}$, respectively, are shaded white. In each snapshot, stars indicate the eddy center, circles show the coordinates of all the stations sampled since the date of the preceding snapshot, and the color scale represents the sea level anomaly (blue in CE, red in AE). Vertical lines and circles in subplots a-d and e-o, respectively, are alternately differentiated in color to distinguish different sets of profiles (a-d) in each snapshot (e-o). The bottom-right corner diagram (p) represents the individual patterns of Pearson's correlation between the depth of isopycnals in the $25.5-27.5 \mathrm{~kg} / \mathrm{m}^{3}$ range, shown in red (isotherms in the $3-23^{\circ} \mathrm{C}$ range, shown in blue) and the depth of the upper/lower limits of the OMZ (dashed and solid lines, respectively), considering the profiles in subplots $3 \mathrm{a}$ to $3 \mathrm{~d}$. DO, dissolved oxygen; OMZ, oxygen minimum zone; WOD, World Ocean Database.

OMZ and a well-marked high-salinity subsurface maximum were followed for a 4-month period between December 3, 2012 to April 2, 2013 (Figures 41-40).

Third, a section sampled $1,400-1,700 \mathrm{~km}$ away from the coast $\left(18-20^{\circ} \mathrm{S}, 84-87^{\circ} \mathrm{W}\right)$ over a 13 -month period in 2015-2016 (Figure 5) provides a very explicit example of the transport of low DO anomalies by ITEs beyond the horizontal, offshore borders of the OMZ. Along this section, profiles with an OMZ were encountered only within lens-shaped structures that satellite altimetry data confirmed to be ITE structures. Four ITEs surrounded by oxygenated water masses (DO $>1 \mathrm{ml} / \mathrm{L}$ ) were actually sampled and detected from altimetry data during the following dates: January 21 to February 9, 2015 (Figure 5e), April 18 to July 16, 2015 (Figures 5g-5i), August 5 to October 13, 2015 (Figures 5j and 5k), and December 11, 2015 to January 19, 2016 (Figures 5m and 5n). Low DO anomalies outside the OMZ are probably not exclusively associated with ITEs; however, the fact that they were only encountered within ITEs in this latter example suggests a noticeable role of ITEs in anomalous deformations of the horizontal climatological boundary of the OMZ (blue line in Figure 1). 


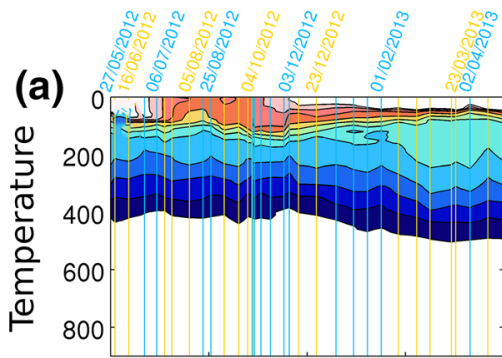

\section{(b)}

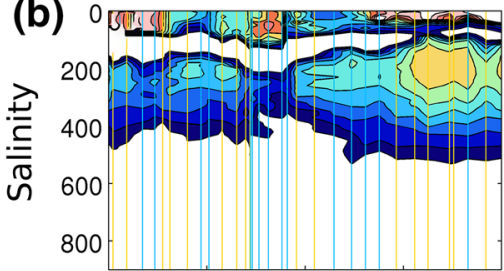

(c)

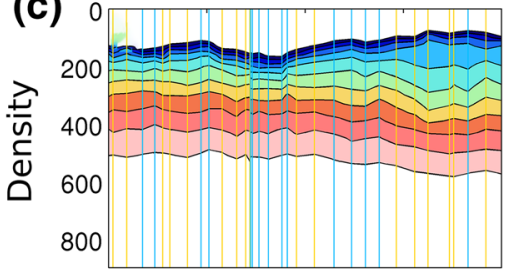

(d)

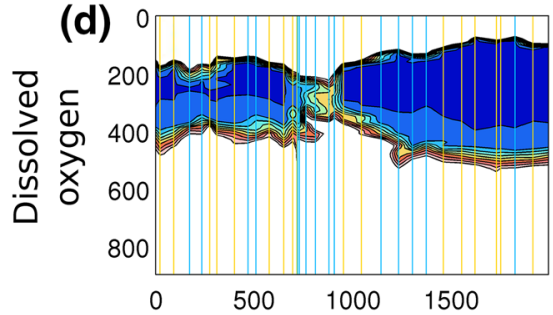

(e)
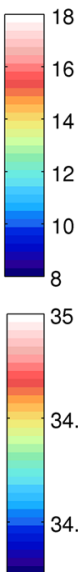

35 (h)

(h)

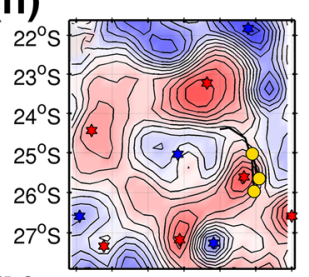

(k)

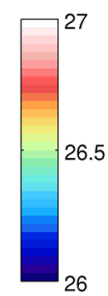

$\square^{1}$ (n)
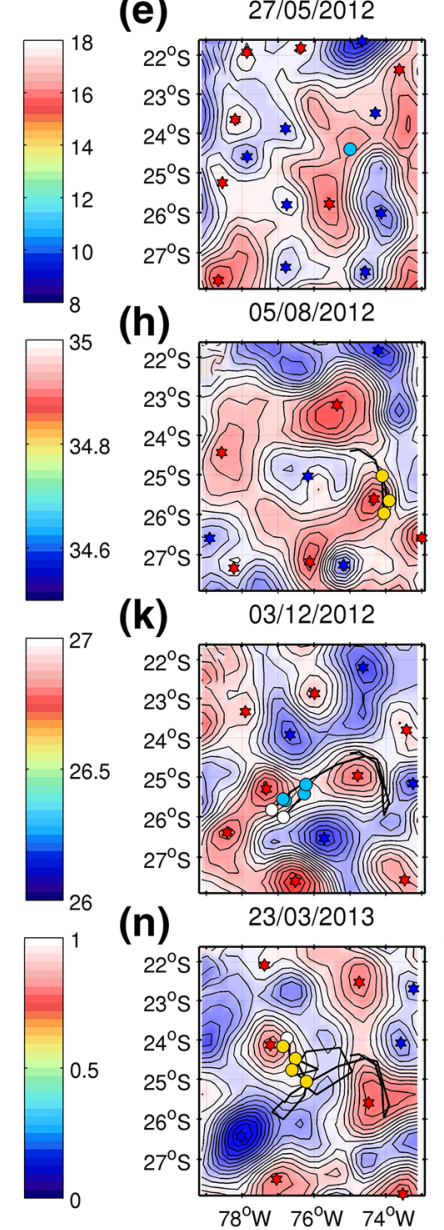

(n)

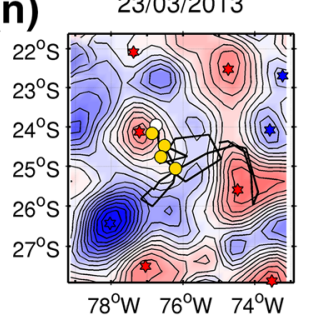

(f)

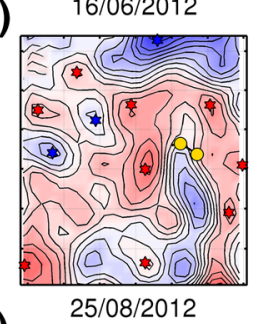

(i)

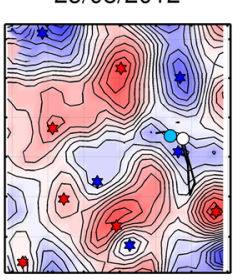

(I)

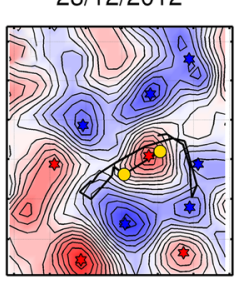

(o)

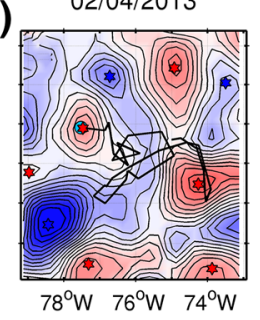

(g)

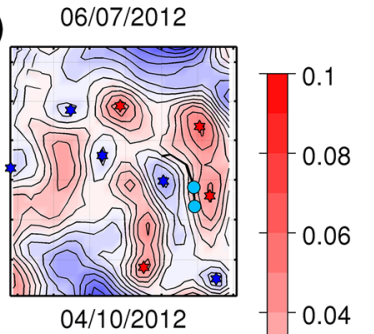

(j)

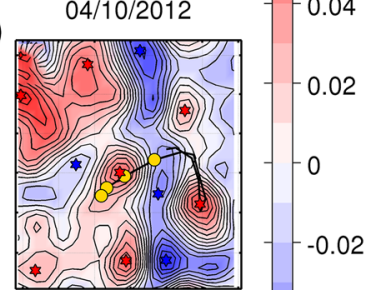

(m)

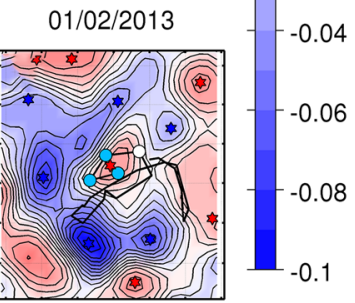

(p)

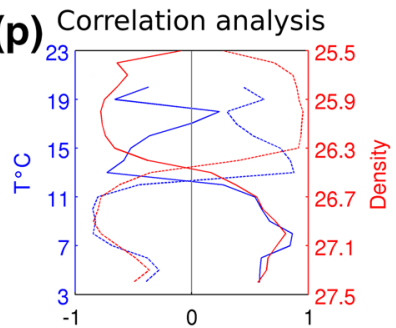

Figure 4. Same as in Figure 3 but for the "99010250" profiling float in the PFL data set (May 27, 2012 to April 2, 2013; WOD2013). (a-d) Vertical lines indicate the profiles considered in the correlation analysis (color) or not (dashed gray). WOD, World Ocean Database.

\subsection{Vertical OMZ Variability Using the Whole Set of Profiles}

In the case of correlation analyses (using 9,506 profiles) performed without including spatiotemporal coherence between profiles (see Section 2.4), the vertical depth anomalies in the climatological OMZ appear to be dominated by a lens-shaped signature (Figure 6). However, latitudinal heterogeneity is detected, and correlations noticeably weaken (especially for the lower oxycline) as the OMZ becomes more intense toward the equator (Figure 1a). The pattern observed in OMZ thickness is very similar to that displayed by depth anomalies in the lower oxycline.

In the coastal band (Figures 6a-6c), three latitudinal subregions can be distinguished. Off southern Peru and Chile (south of $14^{\circ} \mathrm{S}$ ), the correlation patterns for both oxyclines and the OMZ thickness indicate a dominant lens-shaped signature of variability. The density in the core of lens-shaped patterns is estimated to decrease from $26.6 \mathrm{~kg} / \mathrm{m}^{3}$ to $26.4 \mathrm{~kg} / \mathrm{m}^{3}$ and temperature to increase from $11^{\circ} \mathrm{C}$ to $13^{\circ} \mathrm{C}$ (not shown) toward the equator, which is especially clear in the upper oxycline and the OMZ thickness. In a narrow band off central Peru $\left(10-14^{\circ} \mathrm{S}\right)$, such pattern is less clear for the upper oxycline (i.e., a significant negative correlation with the lower isopycnals associated with poorly significant positive ones with the upper isopycnals), whereas the lower oxycline and the OMZ thickness display a vertically coherent signature. Notably, the density in the core of the lens-shaped pattern found for the upper oxycline drops to $26 \mathrm{~kg} / \mathrm{m}^{3}\left(16^{\circ} \mathrm{C}\right.$ for temperature, not shown) in this area. Off northern Peru $\left(0-10^{\circ} \mathrm{S}\right)$, the upper oxycline variability appears to be mainly affected by vertically coherent processes, while those of the lower oxycline and the OMZ 

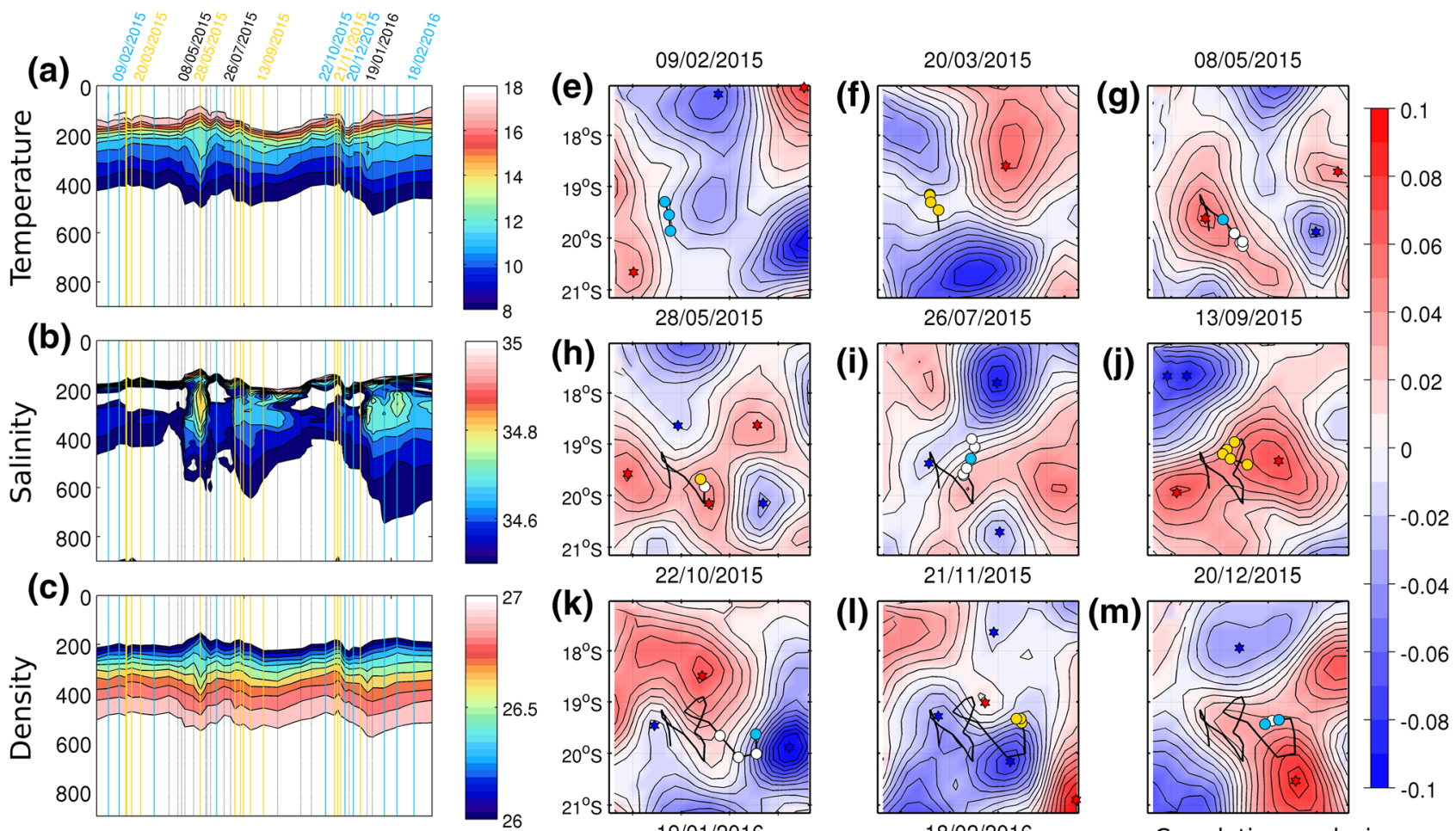

(j)
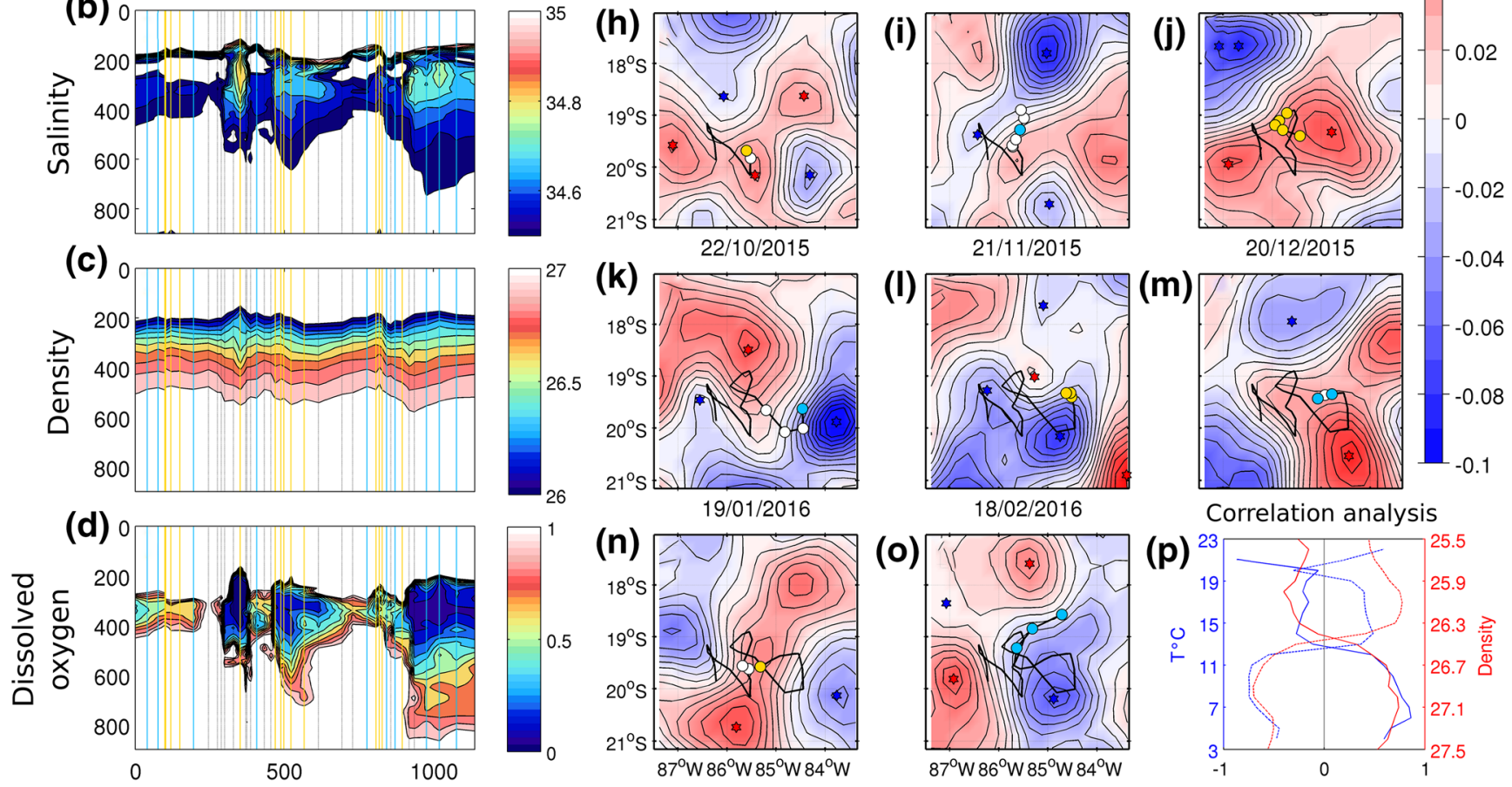

Figure 5. Same as in Figure 4 but for the Argo float 6900527 (January 20, 2015 to February 27, 2016; Argo database).

thickness are dominated by a weak lens-shaped signature with a density of $26.4 \mathrm{~kg} / \mathrm{m}^{3}$ in its core $\left(12^{\circ} \mathrm{C}\right.$ for temperature, not shown).

The correlation patterns obtained by merging all the profiles located in the CTZ $\left(3-10^{\circ}\right.$ from the coast; Figures $6 \mathrm{~d}-6 \mathrm{f}$ ) are similar to those in coastal waters, but the lens-shaped signature is more clearly detected especially off central Peru $\left(10-14^{\circ} \mathrm{S}\right)$, where the density in the core of the lens-shaped pattern $\left(26.4 \mathrm{~kg} / \mathrm{m}^{3}\right)$ is not found to drop as in the coastal band. In offshore waters beyond the CTZ (10-40 from the coast; Figures $6 \mathrm{~g}-$ 60 ), the subregion with a dominant lens-shaped signature expands slightly toward the equator (up to $6^{\circ} \mathrm{S}$ ), but significant correlations progressively disappear toward the southern latitudes. This pattern is explained by the tongue distribution of the OMZ in the ESP (Figure 1a), with decreasing offshore extension toward the pole, so that the number of offshore profiles falling in the OMZ gradually decreases with increasing latitude.

\subsection{Vertical OMZ Variability in the Mesoscale Field}

The role of mesoscale processes, especially eddies, on the vertical OMZ variability can be deduced from correlation analyses of the vertical displacements of the oxyclines and isopycnals/isotherms between profiles resolving the mesoscale (see Section 2.4), further associated with a collocation of CTD-O (1928-2013) and Argo profiles (2000-2016) with satellite altimetry data (1993-2016) and an objective detection of mesoscale eddies (see Section 2.2). Figure 7 presents a focus on the upper oxycline because of its higher relevance to biogeochemical cycles and the distribution of pelagic organisms in regions with intense OMZs. 


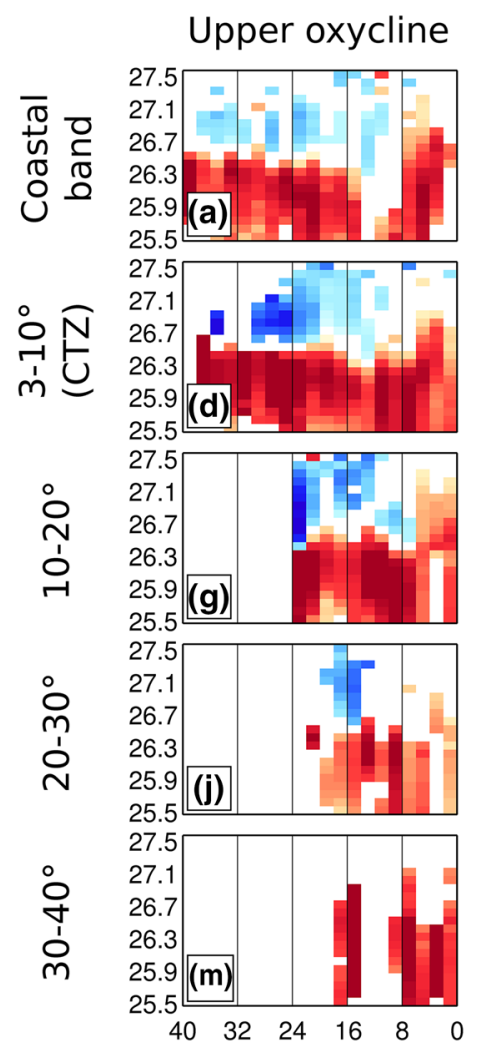

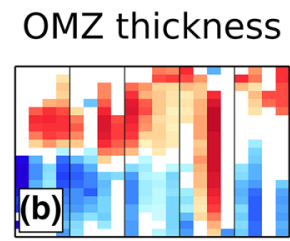
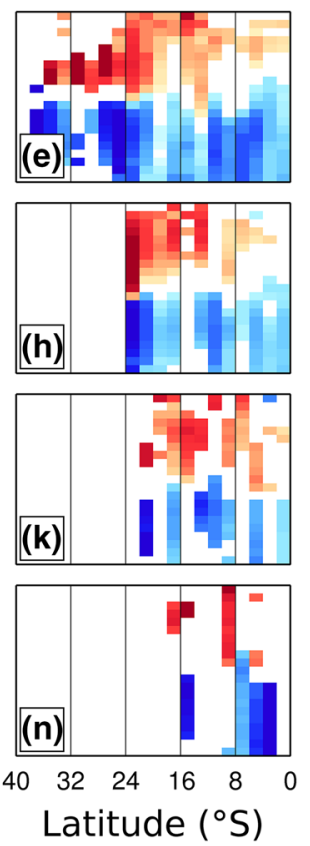

Lower oxycline
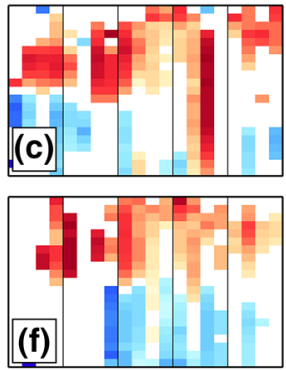

0.8

0.7

0.6

$-0.5$

$-0.4$

$-0.3$

$-0.2$

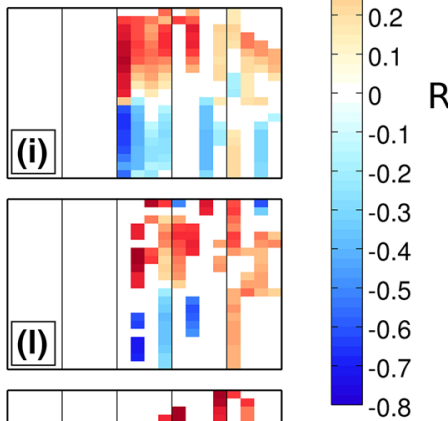

(o)

$\begin{array}{llllll}40 & 32 & 24 & 16 & 8 & 0\end{array}$

Figure 6. Diagrams of Pearson's correlations among depth anomalies in the upper oxycline (left), the OMZ thickness (center) and the lower oxycline (right) with respect to the depth anomalies of isopycnals in the $25.5-27.5 \mathrm{~kg} / \mathrm{m}^{3} \mathrm{range}$ at different meridional ( $y$-axis) and latitudinal bands ( $x$-axis), without considering spatiotemporal coherence in the hydrographic profiles over the 1928-2016 period (see Section 2.4). Only significant correlations $(p<0.05)$ are colored. A negative correlation between the depth of the upper (lower) oxycline and the depth of the lower (upper) isopycnals/ isotherms, together with a positive correlation with those of the upper (lower) isopycnals/isotherms, indicates that the upper (lower) oxycline is dominated by a lens-shaped signature. OMZ, oxygen minimum zone.

In comparing with the previous analysis (Section 3.2) which did not account for spatio-temporal coherence between profiles (see Figure 6), correlation patterns obtained from the displacements of the upper oxycline at the mesoscale (1928-2016 period; Figure 7, first column) are found to be very similar, but correlations are noticeably lower and less significant; the same result is obtained for the lower oxycline analyses (not shown). This demonstrates the importance of mesoscale processes in driving the vertical OMZ variability south of $8^{\circ} \mathrm{S}$ in the coastal band and the CTZ and, to a lesser extent, in offshore waters south of $4^{\circ} \mathrm{S}$. North of those latitudes, the mesoscale variability in both oxyclines appears to be mostly dominated by a weak influence of vertically coherent processes.

When restricting the latter correlation analyses to the period covered by satellite altimetry data (1993-2016; Figure 7, second column) to evaluate more specifically the impact of mesoscale eddies on the vertical OMZ boundaries, correlation patterns are similar to those described for the 1928-2016 period (Figure 7, first column). They are only slightly modified in the coastal band and the CTZ (Figures $7 \mathrm{f}$ and $7 \mathrm{~g}$ ), while remaining nearly unchanged beyond the CTZ (Figures $7 \mathrm{~h}-7 \mathrm{j}$ ). In the coastal band, the vertically coherent signature off northern Peru $\left(<8^{\circ} \mathrm{S}\right.$; Figure $7 \mathrm{a}$ ) is lost (Figure 7f) and the same occurrs in the CTZ (Figure $7 \mathrm{~g}$ ) for the lens-shaped signatures north of $16^{\circ} \mathrm{S}$ (Figure $7 \mathrm{~b}$ ). Thus, it was not possible to evaluate the role of mesoscale eddies in these areas.

The vertically coherent displacements detected in the CTZ and further offshore off northern Peru $\left(0-8^{\circ} \mathrm{S}\right.$; Figures 7g and 7h) are encountered both inside and outside eddies (Figures 7l, 7m, 7q, 7r, 7v, and 7w), which 


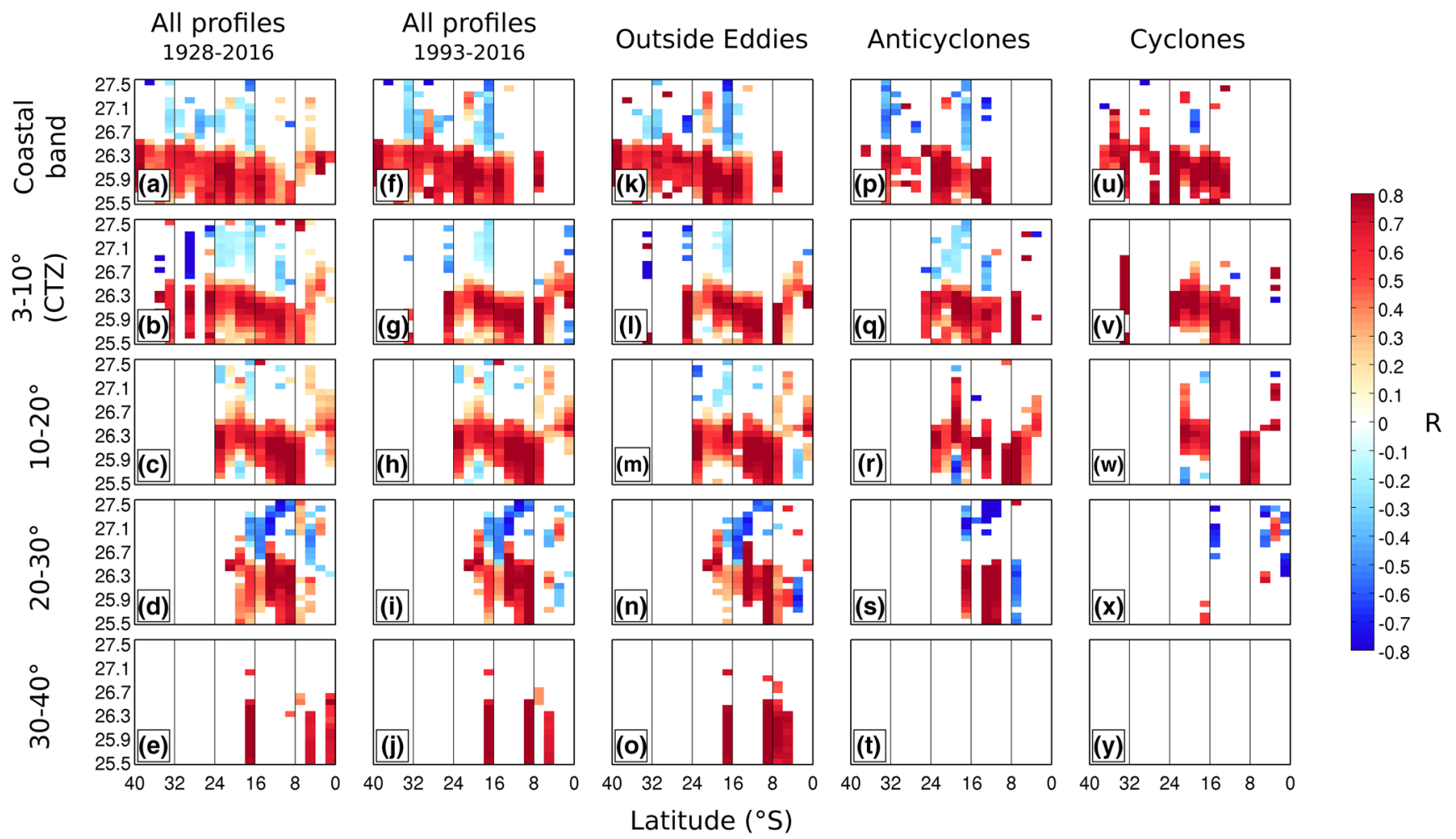

Figure 7. Diagrams of Pearson's correlations between vertical displacements under the mesoscale field of the upper oxycline and of isopycnals in the 25.5$27.5 \mathrm{~kg} / \mathrm{m}^{3}$ range ( $y$-axis) of the latitudinal range ( $x$-axis). Data from all profiles in the 1928-2016 period (first column) and 1993-2016 period (satellite altimetry available), the latter of which includes all the profiles (second column), and only those located outside eddies (third column), inside AEs (fourth column) or inside CEs (fifth column) are shown. Only significant correlations $(p<0.05)$ are colored.

suggests that the mesoscale eddies involved are surface eddies. By contrast, south of $8^{\circ} \mathrm{S}$, a large part of the lens-shaped signature, observed when all profiles are considered (Figure 7, second column), can be attributed to vertical displacements outside eddies (Figure 7, third column). However, displacements in AEs also appear to explain an important part of this lens-shaped signature (Figure 7, fourth column). Particularly, the lens-shaped signature encountered in the CTZ on the southern flank of the OMZ (16-26 $6^{\circ}$, Figure $7 \mathrm{~g}$ ) is almost exclusively due to AEs (Figure 7q). In the coastal band (Figure 7p) and the offshore subdomains beyond the CTZ (10-40 from the coast, Figures $7 \mathrm{r}-7 \mathrm{t}$ ), AEs also explain some patterns of lens-shaped signatures encountered at specific locations (see Section 4.2.1), which are not explained by displacements observed outside eddies or inside CEs (Figure 7, third and fifth columns). Given their lens-shaped signature, these AEs are likely to be subsurface-intensified ITEs. In CEs, a vertically coherent signature is primarily found (Figure 7, fifth column), which corresponds to the vertical displacements of the isopycnals commonly observed in surface-intensified eddies.

The importance of the lens-shaped signature in the vertical OMZ variability at the mesoscale was also evaluated through the proportion of individual sections within each subdomain, for which a significant negative correlation was found between the displacements of the upper (lower) oxycline and lower (upper) isopycnals ( $p<0.05$ for at least one isopycnal in the $25.5-27.5 \mathrm{~kg} / \mathrm{m}^{3}$ range; Figure 8 ). Individual sections are considered to consist of all profiles, or only profiles outside eddies, inside CEs or inside AEs in these sections. Although based on a small number of sections ( $<20$; Figures $8 \mathrm{a}-8 \mathrm{~d})$, this analysis confirms the results in Figure 7 (see above). For both oxyclines, this proportion is generally higher when considering only profiles outside eddies or inside AEs (Figures $8 \mathrm{f}, 8 \mathrm{~g}, 8 \mathrm{j}$, and $8 \mathrm{k}$ ) than when considering profiles inside CEs (Figure $8 \mathrm{~h}-8 \mathrm{l}$ ). The mesoscale variability in the upper oxycline is confirmed to be ubiquitously dominated by a lens-shaped signature south of $8^{\circ} \mathrm{S}$ (Figure 8e). The proportion is higher when profiles are located inside AEs (Figure 8g) compared to outside eddies or inside CEs (Figures $8 \mathrm{f}-8 \mathrm{~h}$ ), in both the coastal band off northern Chile-southern Peru $\left(18-22^{\circ} \mathrm{S}\right)$ and the CTZ (to $20^{\circ}$ from the coast) in the southern border of 
Number of sections
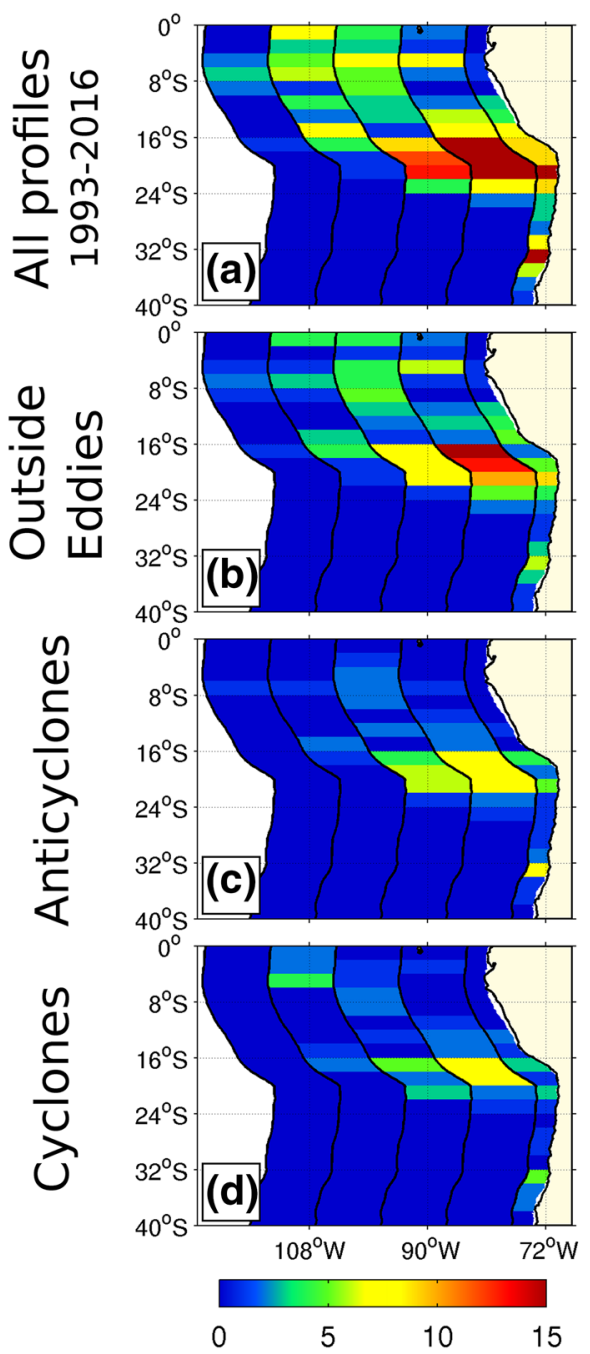

Upper oxycline
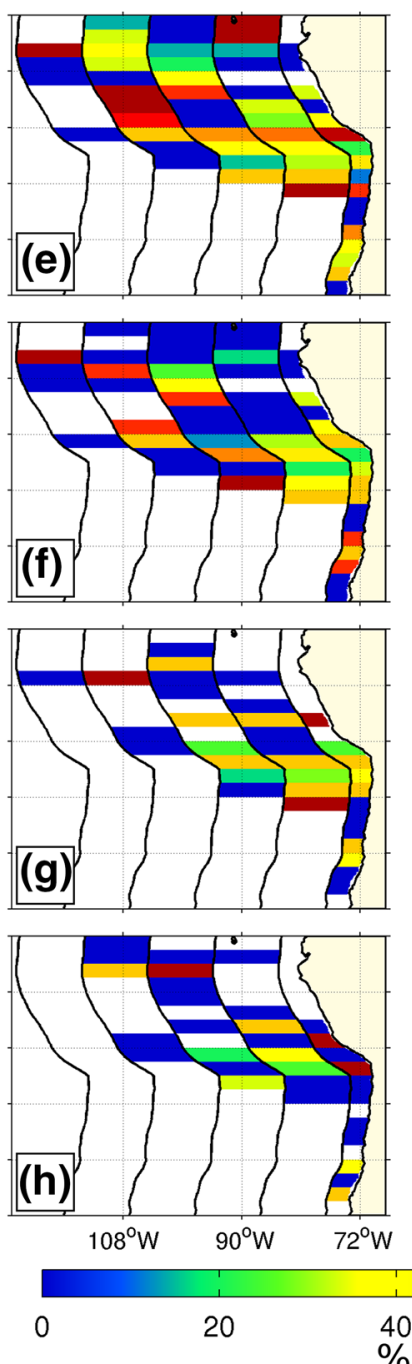

\section{Lower oxycline}
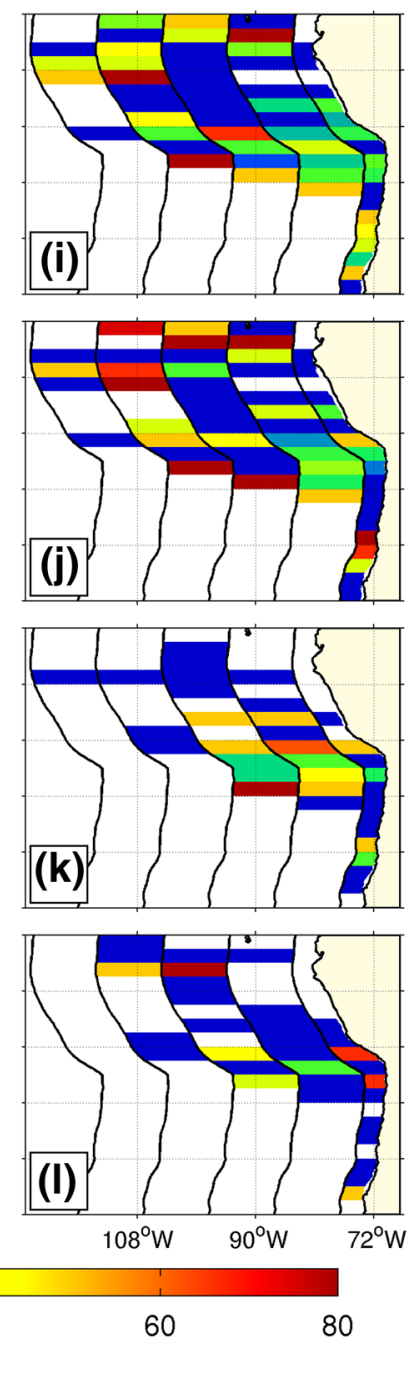

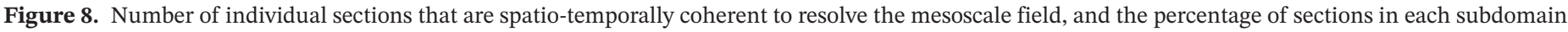

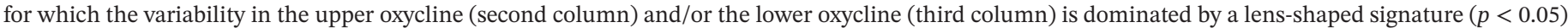

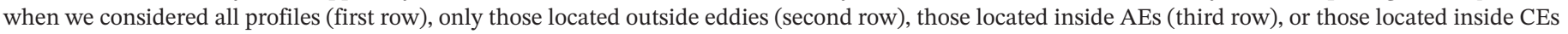
(fourth row).

the OMZ off northern Chile and Peru (north of $26^{\circ} \mathrm{S}$ ). This AEs imprint is lost further offshore, where the lens-shaped signature is mostly found for profiles outside eddies (Figure 8f). Figure 8 also demonstrates that the mesoscale variability in the lower oxycline is mostly dominated by a lens-shaped signature in the horizontal borders of the OMZ (i.e., in the CTZ equatorward of $6^{\circ} \mathrm{S}$ and in the southern border of the OMZ outside the coastal band; Figure 8i). This lens-shaped signature is generally dominant outside eddies and inside CEs in the coastal band and in offshore waters beyond $20^{\circ}$ from the coast (Figures $8 \mathrm{j}-81$ ), while it is dominant in AEs only in the CTZ (to $20^{\circ}$ from the coast) and in the southern border of the OMZ (Figure 8k).

A quantitative measure of the effect of mesoscale eddies on upper oxycline variability is provided by analyzing the vertical displacements observed between profiles outside eddies, inside CEs and inside AEs. The distribution of the absolute displacements of the upper oxycline is shown for each meridional band. Profiles with a lens-shaped signature were separated from those showing vertically coherent displacements (dots and lines, respectively; Figure 9). It is noteworthy that the distributions were normalized by the total num- 


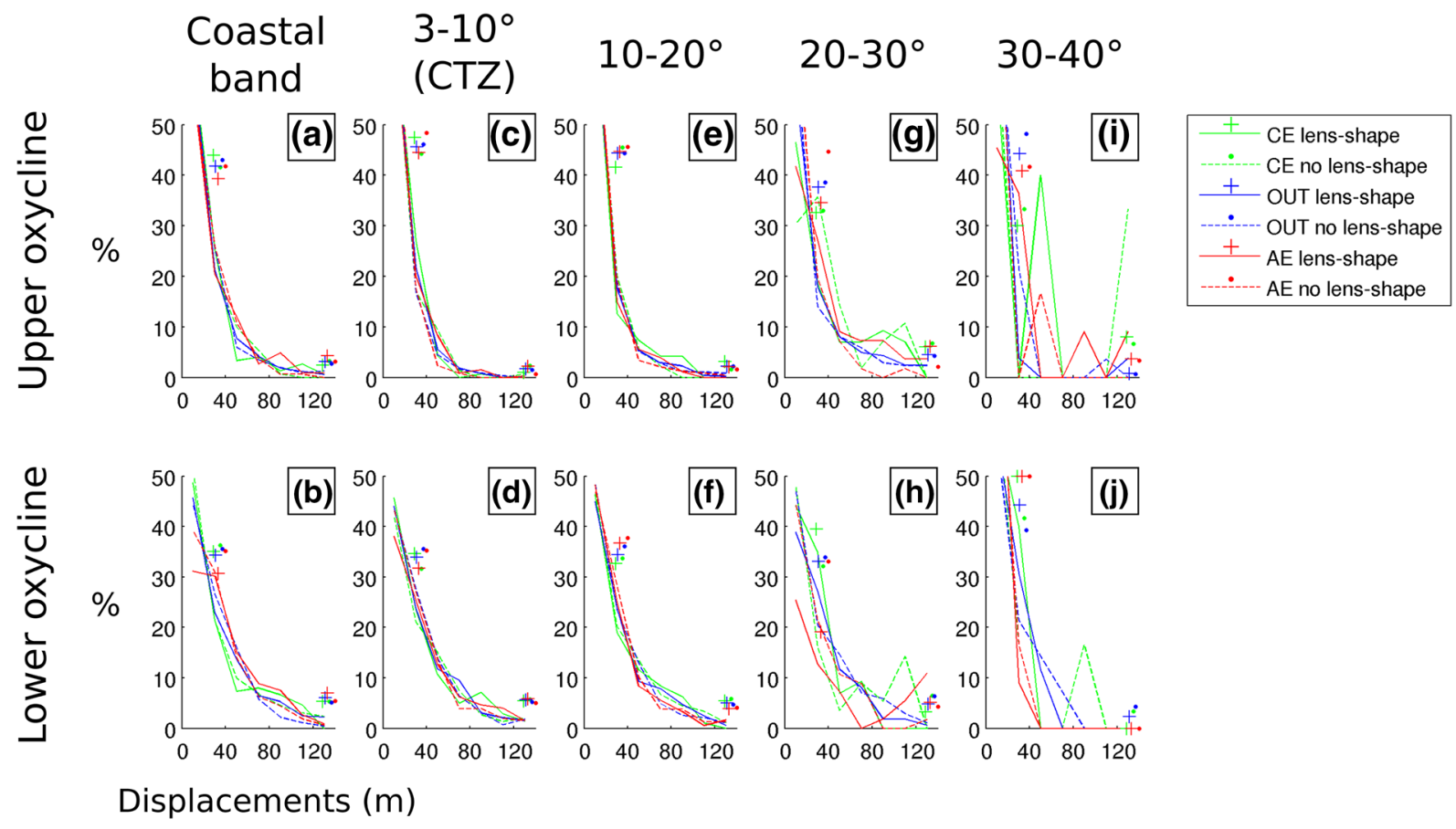

Figure 9. Distribution of the displacements of the upper oxycline between profiles located outside eddies (blue), inside AEs (red) and inside CEs (green) in each meridional band. Dotted lines (solid lines) are for displacements that lead (do not lead) to a lens-shaped signature. Each distribution was normalized by the total number of profiles used to calculate it and is then expressed in the percent of profiles in each category. Dots (crosses) indicate the average probabilities for having displacements $<40 \mathrm{~m}(>40 \mathrm{~m})$.

ber of profiles available in each category, since the number of profiles detected outside eddies is an order of magnitude higher than inside eddies, so they are expressed in \%. The distribution for profiles outside eddies, inside CEs and inside AEs are very similar. Yet, the displacements inside AEs (red) are slightly greater than those outside eddies (blue) or inside CEs (green) when $>40 \mathrm{~m}$ and the opposite is found for those $<40 \mathrm{~m}$. Thus, there is a slightly higher probability of observing important displacements $(>40 \mathrm{~m})$ inside AEs than outside AEs. This fact is especially evident in the coastal band (Figures 9a and 9b), as well as in offshore waters beyond the CTZ $\left(20-40^{\circ}\right.$ from the coast; Figures $9 \mathrm{~g}$, 9h, 9i and 9j). The same pattern is found when comparing displacements associated with lens-shaped and vertically coherent signatures. A higher percentage of displacements $>40 \mathrm{~m}$ is generally found when displacements are associated with a lens-shaped signature, and the opposite is found for displacements $<40 \mathrm{~m}$.

\section{Discussion}

\subsection{A Dominant Lens-Shaped Pattern of Vertical OMZ Variability}

The dominance of either lens-shaped or vertically coherent signatures in the vertical OMZ variability, which emerged in our correlation analyses, depends on the local expression (amplitude) and the recurrence of perturbations induced in the isotherms/isopycnals/oxyclines by a variety of physical processes. All these processes have a wide range of wavelengths and temporal frequencies, and the vertical displacements that they produce can vary by one order of magnitude (from $30 \mathrm{~m}$ to $250 \mathrm{~m}$ ) off Peru and Chile. Then, our correlation analyses are biased by nonhomogeneous spatiotemporal sampling of the WOD2013 and Argo datasets. It is also worth mentioning that the temporal resolution of our data set (at best daily) does not resolve high frequency internal waves, which usually affect the upper oxycline along the shelf break off Peru and display a lens-shaped signature of isopycnals (Grados et al., 2016).

Our analysis of WOD2013 and Argo data in the eastern South Pacific suggests that vertical anomalies in the climatological OMZ mostly take the form of opposite vertical displacements of the upper and lower 
oxyclines. Since this is generally associated with opposite vertical displacements of the seasonal and permanent pycnoclines, this lens-shaped signature can be attributed to physical rather than biological processes. As expected, our results indicate that a great part of this lens-shaped vertical OMZ variability has nothing to do with mesoscale processes, which is noticeably the case for the lower oxycline near the equator and the upper oxycline at the southern border of the OMZ (see Sections 3.2 and 3.3). Changes in the horizontal distribution of water properties at the regional scale are caused by long-term trends (e.g., ocean deoxygenation; Breitburg et al., 2018), low-frequency wave activity and changes in the mean circulation which affect the depth of the upper and lower oxyclines. For instance, the interannual equatorial waves associated with the eastern Pacific El Niño modify the circulation through the radiation of extratropical Rossby waves (Ramos et al., 2008; Vega et al., 2003) and the geostrophic adjustment forced by the poleward advection of equatorial warm waters (Colas et al., 2008; Dewitte et al., 2012), and such events are associated with a deepening of the upper oxycline (Morales et al., 1999). The seasonal to interannual variability in the Equatorial Current System (Kessler \& Gourdeau, 2006) also leads to fluctuations in the water mass transport by the PCUC (Combes et al., 2015; Pizarro-Koch et al., 2019) which is another source of variability for both oxyclines.

Notably, vertically coherent signatures are only found for the upper oxycline off northern Peru (north of $\left.10^{\circ} \mathrm{S}\right)$ and the lower oxycline off central Peru $\left(10-14^{\circ} \mathrm{S}\right)$. Off northern Peru, this suggests a direct impact of low-frequency wave activity (Belmadani et al., 2012; Echevin et al., 2014; Huyer et al., 1987), while off central Peru this could result from the preferential generation of Rossby waves by intraseasonal coastal-trapped waves in this area (Belmadani et al., 2012).

\subsection{Impact of ITEs on the Vertical OMZ Variability in the Mesoscale Field}

Mesoscale processes do contribute to the lens-shaped signature in the vertical OMZ variability south of $8^{\circ} \mathrm{S}$ in the coastal band and the CTZ, and south of $4^{\circ} \mathrm{S}$ further offshore, and most of this is clearly attributed to AEs at specific locations in the coastal band and in the southern border of the OMZ in the CTZ (3-20 from the coast). Their lens-shaped signature suggests that they are actually subsurface-intensified ITEs. Notably, the smoothing process applied to some noisy profiles (Section 2.1) likely reshapes some fine-scale vertical variability in the upper and lower oxycline, but we verified that this process does not create artificial structures resembling ITEs (not shown). As discussed in the following section, the observed meridional changes in the influence of ITEs on the vertical OMZ variability in the coastal band are in line with previous observational and modeling evidence in the ESP.

\subsubsection{Coastal Waters}

In coastal waters of Chile ( south of $14^{\circ} \mathrm{S}$ ), the density in the core of lens-shaped patterns from correlation analyses are estimated to increase poleward from $26.4 \mathrm{~kg} / \mathrm{m}^{3}$ to $26.6 \mathrm{~kg} / \mathrm{m}^{3}$ (Figures $6 \mathrm{a}-6 \mathrm{c}$ ) and temperature to decrease from $13^{\circ} \mathrm{C}$ to $11^{\circ} \mathrm{C}$ (not shown). These trends are in fair agreement with the poleward evolution of water mass properties in the PCUC (Silva et al., 2009) and the available observations of young ITEs off Peru (Stramma et al., 2013; Thomsen et al., 2016) and Chile (Hormazabal et al., 2013; Morales et al., 2012). This finding is consistent with the mixing of the ESSW transported by the Peru-Chile Undercurrent with the colder and denser SAAW off Peru and Chile (Silva et al., 2009).

In the coastal area, ITEs have only been detected off southern Peru (12-18 ${ }^{\circ}$; Altabet et al., 2012; Stramma et al., 2013; Thomsen et al., 2016) and central-southern Chile (28-38 S; Hormazabal et al., 2013; Morales et al., 2012). This corresponds to the latitudes where lens-shaped patterns clearly emerge in the variability in the upper oxycline inside AEs (Figure 7). A subsurface eddy detection analysis based on a multidecadal hydrodynamic modeling study in the ESP (Combes et al., 2015), in fair agreement with the latter observations, suggests that ITEs are preferentially generated off southern Peru $\left(12-18^{\circ} \mathrm{S}\right)$ and central-southern Chile $\left(22-40^{\circ} \mathrm{S}\right)$, while they are rare north of $12^{\circ} \mathrm{S}$ off Peru. Thus, ITEs appear to dominate the upper oxycline variability precisely where their presence has been observed and simulated (see Figure 7 and Section 3.2). By contrast, ITEs do not affect the variability in the lower oxycline off southern Peru (12-18 $\mathrm{S}$, not shown). In this area, the lower oxycline (Fuenzalida et al., 2009) indeed stands below the depth range occupied by ITEs (<600 m; Hormazabal et al., 2013; Stramma et al., 2013, 2014). 
An increasing influence of ITEs on the vertical OMZ variability from Peru to Chile would be expected from the poleward attenuation of low-frequency waves (Belmadani et al., 2012). However, the lens-shaped signature at the mesoscale in the coastal band off Chile is mostly due to vertical displacements outside eddies. At the southern tip of the OMZ, the PCUC indeed undergoes large variability at the intraseasonal scale (20-90 days; Illig et al., 2018a, 2018b), which likely overwhelms the effect of ITEs on the vertical OMZ variability at the mesoscale level.

\subsubsection{Offshore Waters}

The signature of ITEs in offshore waters is generally found on the southern border of the OMZ for both the upper and lower oxyclines. In agreement with cross-shore sections of water mass properties in the ESP (Silva et al., 2009), the core of the lens-shaped patterns makes colder and denser from the coast to the CTZ and beyond it (Figure 7). This is especially true from $10^{\circ} \mathrm{S}$ to $22^{\circ} \mathrm{S}$ (southern Peru), where the density in the core of lens-shaped patterns increases by $\sim 0.3 \mathrm{~kg} / \mathrm{m}^{3}$ between the $3-10^{\circ}(\mathrm{CTZ})$ and $20-40^{\circ}$ bands. ITEs are found to dominate the vertical OMZ variability in the CTZ (3-20 from the coast) south of $16^{\circ} \mathrm{S}$ (Figure 7), implying that surface eddies, barotropic modes of Rossby waves and Ekman pumping (see Introduction) only play a minor role in this area. This finding suggests an impact of ITEs on the offshore extension of the coastal OMZ. Based on Argo and satellite altimeter data, Pegliasco et al. (2015) estimated that 55\% of all anticyclones in the Peru-Chile upwelling system are subsurface-intensified. This estimate agrees with the probability (generally lower than 60\%) of finding the lower oxycline variability inside AEs being dominated at the mesoscale by a lens-shaped signature (Figure 8). However, the same probability for the upper oxycline generally ranges between $40 \%$ and $80 \%$. Such a surprising feature may simply result from greater displacements of the lower isopycnals in ITEs compared with surface AEs, while the difference in displacements of the upper oxycline is comparatively weak. Beyond the CTZ $\left(20-30^{\circ}\right.$ from the coast), the lens-shaped signature in the upper and lower oxycline variability is mostly driven by vertical displacements outside eddies (Figure 7). However, the sea surface height signature of ITEs is weak in the offshore region (Frenger et al., 2018; Stramma et al., 2014). Hence, we expect that some profiles sampling ITEs have been erroneously classified as being outside eddies, which may lead to underestimating the effect of ITEs on the upper oxycline variability in offshore waters beyond the CTZ.

\subsubsection{Impact of ITEs on the Horizontal Shape of the OMZ}

Making the assumption of uniform dissipation rates of ITEs in the ESP and a poleward oxygenation of the Peru-Chile Undercurrent, the latter result raises the question of whether or not the shape of the large-scale OMZ in the ESP, characterized by a decreasing offshore extension toward the pole (Fuenzalida et al., 2009), may partly arise from a combination of slowing westward eddy propagation (Chaigneau et al., 2009) and increasing oxygenation in ITEs toward the pole (Silva et al., 2009). This finding would imply that interannual variations in the shape of the large-scale OMZ in the ESP (including the potential role of ITEs in OMZ ventilation) are affected by the volume of ITEs generated near the coast and by the intensity of transport by the Peru-Chile Undercurrent, which carries low-oxygen anomalies poleward along the coast. In a modeling study, Combes et al. (2015) found that while the transport by the Peru-Chile Undercurrent increases, the number and volume of ITEs decrease during strong El Niño events. These authors speculated that this occurrence was due to a weakening of baroclinic instability caused by the relaxation of isopycnals along the coasts off Peru and Chile. Although very speculative, the large-scale OMZ may concomitantly contract toward the coast and expand poleward during El Niño events (and the opposite would occur during La Niña) with potential implications for the spatial distribution of marine organisms/populations whose habitats are constrained by oxygen availability (Bertrand et al., 2011). This idea should be tested using modeling approaches.

Even if ITEs do not noticeably drive the large-scale distribution of the OMZ, the horizontal borders of the OMZ are likely to be shaped by the low DO anomalies hosted by ITEs. As shown in our series of examples (see Section 3.1), ITEs indeed propagate westward, transporting low DO anomalies trapped in the coastal core of the large-scale OMZ (Hormazabal et al., 2013; Thomsen et al., 2016) toward more oxygenated off- 
shore waters. Thus, ITEs together with surface CEs (Chaigneau et al., 2011) actively modulate ventilation processes at the horizontal borders of the OMZ through cross-gradient horizontal eddy advection (Bettencourt et al., 2015; Vergara et al., 2016).

\subsection{Potential Influence of ITEs on the Marine Food Web}

North of $12^{\circ} \mathrm{S}$, the distribution of fish communities in the surface ocean likely responds to the variability in the upper oxycline at the mesoscale level due to both surface eddies and coastal-trapped waves and at the submesoscale level due to fronts and internal waves (Grados et al., 2016). South of $12^{\circ} \mathrm{S}$, we found that ITEs strongly affect the variability in the depth of the upper oxycline in the CTZ, bringing very low-oxygen anomalies close to the surface (50-100 m depth; Hormazabal et al., 2013; Stramma et al., 2013).

Mesoscale eddies can host high levels of plankton biomass compared with the surrounding waters, thereby causing aggregation patterns of pelagic fishes (Gaube et al., 2014; Godø et al., 2012; Hormazabal et al., 2013; Logerwell \& Smith, 2001; Nakata et al., 2000) and top predators (Tew Kai \& Marsac, 2010). At the same time, the compression of the fish habitat always occurring on top of ITEs could locally exclude species and/ or modify predator-prey relationships (Gilly et al., 2013; Prince \& Goodyear, 2006). The foraging success of large predators may be enhanced due to increased ambient light and prey concentration in the narrow surface-oxygenated layer on top of ITEs, while the possibility for prey to hide from predation at depth is limited by hypoxia (Gilly et al., 2013). Fish may also be easier to catch in human fisheries on top of ITEs (Bertrand et al., 2011; Stramma et al., 2011). Thus, the generation of ITEs at the coast may contribute to reducing the habitat volume for fish (Bertrand et al., 2004, 2010) and to spatially structuring the food web at the mesoscale level along the southern border of the OMZ, especially in the CTZ, as already suggested in the productive coastal area off Peru (Bertrand et al., 2004, 2008).

It is worth mentioning that the influence of ITEs on the food web may be modulated at the interannual scale by ENSO variability, and at longer time scales, it may also strengthen in the future. The current shoaling of the OMZ due to global deoxygenation already tends to compress the vertical habitat of high-oxygen-demand pelagic fishes and large predators (Stramma et al., 2011). On the one hand, the effects of ITEs should increase with a shallower OMZ, as observed during La Niña events (Chavez, 2003) and as expected under a scenario of increased stratification led by global warming (Echevin et al., 2012; Oerder et al., 2015) and/or ocean deoxygenation (Breitburg et al., 2018; Keeling et al., 2010; Stramma et al., 2008). On the other hand, the number and volume of ITEs may increase during La Niña events, and the opposite may occur during El Niño (Combes et al., 2015). An intensification of the Peru-Chile Undercurrent under global warming (Oerder et al., 2015) may also lead to more ITEs through stronger perturbations of its flow (Thomsen et al., 2016). The food web may then be affected by an intensification of ITE activity under global warming, especially during La Niña events if ITEs are more frequent and the OMZ is shallower during such events.

\section{Conclusion}

The unique signature that ITEs leave on the vertical distribution of temperature, salinity and DO concentration provides a clue to the mechanisms that drive the mesoscale variability in the vertical OMZ boundaries in the ESP region. We propose that a great part of the fluctuations in the upper and/or lower oxycline at the mesoscale comes from the activity of ITEs beyond the coastal band. We found that ITEs are the most relevant source of variability for the upper oxycline in the CTZ and probably also further offshore on the southern border of the OMZ. This finding suggests that the low DO anomalies transported by ITEs contribute to shaping the horizontal borders of the OMZ. Depth variations of the surface-oxygenated layer induced by ITEs may affect the habitat volume for fish as well as for other organisms in the surface layer, creating mesoscale variability in the structure of marine food webs and in carbon export. An intensification of ITE activity coupled with OMZ shoaling, in the context of global warming and ocean deoxygenation, would probably amplify their effects on food web functioning. Modeling strategies that couple state of the art physical-biogeochemical-ecological modeling should then be applied to verify the present findings and to assess the potential indirect effect of ITEs on the marine food web. 


\section{Data Availability Statement}

The data set used in this work are available in SEANOE (SEA scieNtific Open data Edition; https://doi. org/10.17882/74336).

\section{Acknowledgments}

The authors wish to thank the International World Ocean Database and Argo projects and the national programs that contribute to it, as these projects collected and made freely available the set of in situ profiles used in this work. Thanks also to O. Ulloa and O. Pizarro for providing data from Argo floats deployed off Chile with the support of the Agouron Institute (Grant AIMME1.05), to Cesar Hormazábal, Manuel Castillo, and Luis Pizarro for their help with float deployment and to Winston Rojas, Ricardo De Pol-Holz and Salvador Ramírez for data acquisition and processing. Satellite altimetry data were produced by Ssalto/Duacs and distributed by AVISO. The authors are most grateful to Luis Valencia, and two anonymous reviewers for their valuable comments on the results of this study. This research was partially supported by the supercomputing infrastructure of the NLHPC (ECM-02). We also acknowledge the computing time on the Oceano High-Performance Computing Cluster at PUCV, Chile (FONDEQUIP EQM170214). The present work was supported by the Instituto Milenio de Oceanografía (IMO-Chile) and funded by the Iniciativa Científica Milenio (ICM-Chile, ICN12-019), FONDECYT Project 1151299 (C. E. Morales and S. Hormazabal), FONDECYT 1171895 (S. Hormazabal, C. E. Morales, P. A. Auger and J. P. Bento), and FONDECYT 11160801 (P. A. Auger).

\section{References}

Albert, A., Echevin, V., Lévy, M., \& Aumont, O. (2010). Impact of nearshore wind stress curl on coastal circulation and primary productivity in the Peru upwelling system. Journal of Geophysical Research, 115, C12. https://doi.org/10.1029/2010JC006569

Altabet, M. A., Ryabenko, E., Stramma, L., Wallace, D. W. R., Frank, M., Grasse, P., \& Lavik, G. (2012). An eddy-stimulated hotspot for fixed nitrogen-loss from the Peru oxygen minimum zone. Biogeosciences, 9(12), 4897-4908. https://doi.org/10.5194/bg-9-4897-2012

Arévalo-Martínez, D. L., Kock, A., Löscher, C. R., Schmitz, R. A., \& Bange, H. W. (2015). Massive nitrous oxide emissions from the tropical South Pacific Ocean. Nature Geoscience, 8(7), 530-533. https://doi.org/10.1038/ngeo2469

Argo (2000). Argo float data and metadata from Global Data Assembly Centre (Argo GDAC). SEANOE. https://doi.org/10.17882/42182

Assassi, C., Morel, Y., Vandermeirsch, F., Chaigneau, A., Pegliasco, C., Morrow, R., et al. (2016). An index to distinguish surface- and subsurface-intensified vortices from surface observations. Journal of Physical Oceanography, 46(8), 2529-2552. https://doi.org/10.1175/ JPO-D-15-0122.1

Bahl, A., Gnanadesikan, A., \& Pradal, M. -A. (2019). variations in ocean deoxygenation across Earth system models: Isolating the role of parameterized lateral mixing. Global Biogeochemical Cycles, 33(6), 703-724. https://doi.org/10.1029/2018GB006121

Belmadani, A., Echevin, V., Dewitte, B., \& Colas, F. (2012). Equatorially forced intraseasonal propagations along the Peru-Chile coast and their relation with the nearshore eddy activity in 1992-2000: A modeling study. Journal of Geophysical Research, 117, C4. https://doi. org/10.1029/2011JC007848

Bertrand, A., Ballón, M., \& Chaigneau, A. (2010). Acoustic observation of living organisms reveals the upper limit of the oxygen minimum zone. PLOS One, 5(4), e10330. https://doi.org/10.1371/journal.pone.0010330

Bertrand, A., Chaigneau, A., Peraltilla, S., Ledesma, J., Graco, M., Monetti, F., \& Chavez, F. P. (2011). Oxygen: A fundamental property regulating pelagic ecosystem structure in the coastal southeastern Tropical Pacific. PLOS One, 6(12), e29558. https://doi.org/10.1371/ journal.pone.0029558

Bertrand, A., Gerlotto, F., Bertrand, S., Gutiérrez, M., Alza, L., Chipollini, A., et al. (2008). Schooling behaviour and environmental forcing in relation to anchoveta distribution: An analysis across multiple spatial scales. Progress in Oceanography, 79(2-4), 264-277. https://doi. org/10.1016/j.pocean.2008.10.018

Bertrand, A., Segura, M., Gutierrez, M., \& Vasquez, L. (2004). From small-scale habitat loopholes to decadal cycles: a habitat-based hypothesis explaining fluctuation in pelagic fish populations off Peru. Fish and Fisheries, 5(4), 296-316. https://doi. org/10.1111/j.1467-2679.2004.00165.x

Bettencourt, J. H., López, C., Hernández-García, E., Montes, I., Sudre, J., Dewitte, B., et al. (2015). Boundaries of the Peruvian oxygen minimum zone shaped by coherent mesoscale dynamics. Nature Geoscience, 8(12), 937-940. https://doi.org/10.1038/ngeo2570

Bianchi, D., Stock, C., Galbraith, E. D., \& Sarmiento, J. L. (2013). Diel vertical migration: Ecological controls and impacts on the biological pump in a one-dimensional ocean model. Global Biogeochemical Cycles, 27(2), 478-491. https://doi.org/10.1002/gbc.20031

Blanco, J. L., Carr, M. E., Thomas, A. C., \& Strub, P. T. (2002). Hydrographic conditions off northern Chile during the 1996-1998 La Niña and El Niño events. Journal of Geophysical Research, 107, C3. https://doi.org/10.1029/2001JC001002

Bograd, S. J., Castro, C. G., Di Lorenzo, E., Palacios, D. M., Bailey, H., Gilly, W., \& Chavez, F. P. (2008). Oxygen declines and the shoaling of the hypoxic boundary in the California Current. Geophysical Research Letters, 35, 12. https://doi.org/10.1029/2008GL034185

Boyer, T. P., Antonov, J. I., Baranova, O. K., Coleman, C., Garcia, H. E., Grodsky, A., et al. (2013). World Ocean Database 2013, NOAA Atlas NESDIS 72, (pp. 209.), S. Levitus, Ed., A. Mishonov, Technical Ed., MD; Silver Spring, Retrieved from, http://doi.org/10.7289/ V5NZ85MT

Breitburg, D., Levin, L. A., Oschlies, A., Grégoire, M., Chavez, F. P., Conley, D. J., et al. (2018). Declining oxygen in the global ocean and coastal waters. Science, 359(6371), eaam7240. https://doi.org/10.1126/science.aam7240

Cabré, A., Marinov, I., Bernardello, R., \& Bianchi, D. (2015). Oxygen minimum zones in the tropical Pacific across CMIP5 models: Mean state differences and climate change trends. Biogeosciences, 12(18), 5429-5454. https://doi.org/10.5194/bg-12-5429-2015

Capet, A., Mason, E., Rossi, V., Troupin, C., Faugère, Y., Pujol, I., \& Pascual, A. (2014). Implications of refined altimetry on estimates of mesoscale activity and eddy-driven offshore transport in the Eastern Boundary Upwelling Systems. Geophysical Research Letters, 41(21), 7602-7610. https://doi.org/10.1002/2014GL061770

Carr, M.-E., \& Kearns, E. J. (2003). Production regimes in four Eastern Boundary Current systems. Deep Sea Research Part II: Topical Studies in Oceanography, 50(22-26), 3199-3221. https://doi.org/10.1016/j.dsr2.2003.07.015

Chaigneau, A., Eldin, G., \& Dewitte, B. (2009). Eddy activity in the four major upwelling systems from satellite altimetry (1992-2007). Progress in Oceanography, 83(1-4), 117-123. https://doi.org/10.1016/j.pocean.2009.07.012

Chaigneau, A., Le Texier, M., Eldin, G., Grados, C., \& Pizarro, O. (2011). Vertical structure of mesoscale eddies in the eastern South Pacific Ocean: A composite analysis from altimetry and Argo profiling floats. Journal of Geophysical Research, 116(C11), C11025. https://doi. org/10.1029/2011JC007134

Chavez, F. P. (2003). From Anchovies to Sardines and Back: Multidecadal Change in the Pacific Ocean. Science, 299(5604), 217-221. https://doi.org/10.1126/science.1075880

Colas, F., Capet, X., McWilliams, J. C., \& Shchepetkin, A. (2008). 1997-1998 El Niño off Peru: A numerical study. Progress in Oceanography, 79(2-4), 138-155. https://doi.org/10.1016/j.pocean.2008.10.015

Combes, V., Hormazabal, S., \& Di Lorenzo, E. (2015). Interannual variability of the subsurface eddy field in the Southeast Pacific. Journal of Geophysical Research: Oceans, 120(7), 4907-4924. https://doi.org/10.1002/2014JC010265

Contreras, M., Pizarro, O., Dewitte, B., Sepulveda, H. H., \& Renault, L. (2019). Subsurface mesoscale eddy generation in the ocean off Central Chile. Journal of Geophysical Research: Oceans, 124(8), 5700-5722. https://doi.org/10.1029/2018JC014723

Couespel, D., Lévy, M., \& Bopp, L. (2019). Major contribution of reduced upper ocean oxygen mixing to global ocean deoxygenation in an Earth system model. Geophysical Research Letters, 46(21), 12239-12249. https://doi.org/10.1029/2019GL084162

Czeschel, R., Stramma, L., Weller, R. A., \& Fischer, T. (2015). Circulation, eddies, oxygen, and nutrient changes in the eastern tropical South Pacific Ocean. Ocean Science, 11(3), 455-470. https://doi.org/10.5194/os-11-455-2015 
Dewitte, B., Vazquez-Cuervo, J., Goubanova, K., Illig, S., Takahashi, K., Cambon, G., ... Ortlieb, L.. (2012). Change in El Nino flavours over 1958-2008: Implications for the long-term trend of the upwelling off Peru. Deep Sea Research Part II: Topical Studies in Oceanography, 77, 143-156. https://doi.org/10.1016/j.dsr2.2012.04.011

Duteil, O., \& Oschlies, A. (2011). Sensitivity of simulated extent and future evolution of marine suboxia to mixing intensity. Geophysical Research Letters, 38(6), L06607. https://doi.org/10.1029/2011GL046877

Echevin, V., Albert, A., Lévy, M., Graco, M., Aumont, O., Piétri, A., \& Garric, G. (2014). Intraseasonal variability of nearshore productivity in the Northern Humboldt Current system: The role of coastal trapped waves. Continental Shelf Research, 73, 14-30. https://doi. org/10.1016/j.csr.2013.11.015

Echevin, V., Goubanova, K., Belmadani, A., \& Dewitte, B. (2012). Sensitivity of the Humboldt Current system to global warming: a downscaling experiment of the IPSL-CM4 model. Climate Dynamics, 38(3-4), 761-774. https://doi.org/10.1007/s00382-011-1085-2

Ekau, W., Auel, H., Pörtner, H.-O., \& Gilbert, D. (2010). Impacts of hypoxia on the structure and processes in pelagic communities (zooplankton, macro-invertebrates and fish). Biogeosciences, 7(5), 1669-1699. https://doi.org/10.5194/bg-7-1669-2010

Emerson, S., Watanabe, Y. W., Ono, T., \& Mecking, S. (2004). Temporal trends in apparent oxygen utilization in the upper pycnocline of the North Pacific: 1980-2000. Journal of Oceanography, 60(1), 139-147. https://doi.org/10.1023/B:JOCE.0000038323.62130.a0

Frenger, I., Bianchi, D., Stührenberg, C., Oschlies, A., Dunne, J., Deutsch, C., et al. (2018). Biogeochemical role of subsurface coherent eddies in the ocean: Tracer cannonballs, hypoxic storms, and microbial stewpots?. Global Biogeochemical Cycles, 32(2), 226-249. https:// doi.org/10.1002/2017GB005743

Fuenzalida, R., Schneider, W., Garcés-Vargas, J., Bravo, L., \& Lange, C. (2009). Vertical and horizontal extension of the oxygen minimum zone in the eastern South Pacific Ocean. Deep Sea Research Part II: Topical Studies in Oceanography, 56(16), 992-1003. https://doi. org/10.1016/j.dsr2.2008.11.001

Garcia-Robledo, E., Padilla, C. C., Aldunate, M., Stewart, F. J., Ulloa, O., Paulmier, A., et al. (2017). Cryptic oxygen cycling in anoxic marine zones. Proceedings of the National Academy of Sciences, 114(31), 8319-8324. https://doi.org/10.1073/pnas.1619844114

Garcia, H. E., Locarnini, R. A., Boyer, T. P., Antonov, J. I., Baranova, O. K., \& Zweng, M. M. (2014). World Ocean Atlas 2013. S. Levitus \& A. Mishonov (Eds.), Technical Dissolved Oxygen, Apparent Oxygen Utilization, and Oxygen Saturation, (Vol 3, pp. 27-75). NOAA Atlas NESDIS.

Gaube, P., McGillicuddy, D. J., Chelton, D. B., Behrenfeld, M. J., \& Strutton, P. G. (2014). Regional variations in the influence of mesoscale eddies on near-surface chlorophyll. Journal of Geophysical Research: Oceans, 119(12), 8195-8220. https://doi.org/10.1002/2014JC010111

Gilly, W. F., Beman, J. M., Litvin, S. Y., \& Robison, B. H. (2013). Oceanographic and biological effects of shoaling of the oxygen minimum zone. Annual Review of Marine Science, 5(1), 393-420. https://doi.org/10.1146/annurev-marine-120710-100849

Gnanadesikan, A., Dunne, J. P., \& John, J. (2012). Understanding why the volume of suboxic waters does not increase over centuries of global warming in an Earth System Model. Biogeosciences, 9(3), 1159-1172. https://doi.org/10.5194/bg-9-1159-2012

Godø, O. R., Samuelsen, A., Macaulay, G. J., Patel, R., Hjøllo, S. S., Horne, J., et al. (2012). Mesoscale eddies are oases for higher trophic marine life. PLoS One, 7(1), e30161. https://doi.org/10.1371/journal.pone.0030161

Grados, D., Bertrand, A., Colas, F., Echevin, V., Chaigneau, A., Gutiérrez, D., et al. (2016). Spatial and seasonal patterns of fine-scale to mesoscale upper ocean dynamics in an Eastern Boundary Current System. Progress in Oceanography, 142, 105-116. https://doi. org/10.1016/j.pocean.2016.02.002

Helly, J. J., \& Levin, L. A. (2004). Global distribution of naturally occurring marine hypoxia on continental margins. Deep Sea Research Part I: Oceanographic Research Papers, 51(9), 1159-1168. https://doi.org/10.1016/j.dsr.2004.03.009

Hidalgo, P., Escribano, R., \& Morales, C. E. (2005). Ontogenetic vertical distribution and diel migration of the copepod Eucalanus inermis in the oxygen minimum zone off northern Chile (20-21 $\left.{ }^{\circ} \mathrm{S}\right)$. Journal of Plankton Research, 27(6), 519-529. https://doi.org/10.1093/ plankt/fbi025

Hormazabal, S., Combes, V., Morales, C. E., Correa-Ramirez, M. A., Di Lorenzo, E., \& Nuñez, S. (2013). Intrathermocline eddies in the coastal transition zone off central Chile (31- $\left.41^{\circ} \mathrm{S}\right)$ : Intrathermocline eddies off Chile. Journal of Geophysical Research: Oceans, 118(10), 4811-4821. https://doi.org/10.1002/jgrc.20337

Hormazabal, S., Shaffer, G., \& Pizarro, O. (2002). Tropical Pacific control of intraseasonal oscillations off Chile by way of oceanic and atmospheric pathways. Geophysical Research Letters, 29(6). https://doi.org/10.1029/2001GL013481

Huyer, A., Smith, R. L., Paluszkiewicz, T., \& others (1987). Coastal upwelling off Peru during normal and El Niño times, 1981-1984. Journal of Geophysical Research, 92(C13) 14297-14307. https://doi.org/10.1029/JC092iC13p14297

Illig, S., Bachèlery, M. L., \& Cadier, E. (2018). Subseasonal coastal-trapped wave propagations in the Southeastern Pacific and Atlantic Oceans: 2. Wave characteristics and connection with the equatorial variability. Journal of Geophysical Research: Oceans, 123(6), 39423961. https://doi.org/10.1029/2017JC013540

Illig, S., Cadier, E., Bachèlery, M. L., \& Kersalé, M. (2018). Subseasonal coastal-trapped wave propagations in the Southeastern Pacific and Atlantic Oceans: 1. A new approach to estimate wave amplitude. Journal of Geophysical Research: Oceans, 123(6), 3915-3941. https:// doi.org/10.1029/2017JC013539

Jiao, N., Robinson, C., Azam, F., Thomas, H., Baltar, F., Dang, H., et al. (2014). Mechanisms of microbial carbon sequestration in the ocean-Future research directions. Biogeosciences, 11(19), 5285-5306. https://doi.org/10.5194/bg-11-5285-2014

Johnson, G. C., \& McTaggart, K. E. (2010). Equatorial Pacific $13^{\circ} \mathrm{C}$ water eddies in the eastern subtropical South Pacific Ocean. Journal of Physical Oceanography, 40, 226-236. https://doi.org/10.1175/2009JPO4287.1

Kalvelage, T., Lavik, G., Jensen, M. M., Revsbech, N. P., Löscher, C., Schunck, H., et al. (2015). Aerobic microbial respiration in oceanic oxygen minimum zones. PLOS One, 10(7), e0133526. https://doi.org/10.1371/journal.pone.0133526

Karstensen, J., Stramma, L., \& Visbeck, M. (2008). Oxygen minimum zones in the eastern tropical Atlantic and Pacific oceans. Progress in Oceanography, 77(4), 331-350. https://doi.org/10.1016/j.pocean.2007.05.009

Keeling, R. F., Körtzinger, A., \& Gruber, N. (2010). Ocean deoxygenation in a warming world. Annual Review of Marine Science, 2(1), 199-229. https://doi.org/10.1146/annurev.marine.010908.163855

Kessler, W. S., \& Gourdeau, L. (2006). Wind-driven zonal jets in the South Pacific Ocean. Geophysical Research Letters, 33(3), L03608. https://doi.org/10.1029/2005GL025084

Llanillo, P. J., Karstensen, J., Pelegrí, J. L., \& Stramma, L. (2013). Physical and biogeochemical forcing of oxygen and nitrate changes during El Niño/El Viejo and La Niña/La Vieja upper-ocean phases in the tropical eastern South Pacific along $86^{\circ} \mathrm{W}$. Biogeosciences, 10(10), 6339-6355. https://doi.org/10.5194/bg-10-6339-2013

Llanillo, P. J., Pelegrí, J. L., Talley, L. D., Peña-Izquierdo, J., \& Cordero, R. R. (2018). Oxygen pathways and budget for the eastern South Pacific oxygen minimum zone. Journal of Geophysical Research: Oceans, 123(3), 1722-1744. https://doi.org/10.1002/2017JC013509 
Logerwell, E. A., \& Smith, P. E. (2001). Mesoscale eddies and survival of late stage Pacific sardine (Sardinops sagax) larvae. Fisheries Oceanography, 10(1), 13-25. https://doi.org/10.1046/j.1365-2419.2001.00152.x

Locarnini, R. A., Mishonov, A. V., Antonov, J. I, Boyer, T. P., Garcia, H. E., Garcia, O. K., et al., (2013). World Ocean Atlas 2013. S. Levitus \& A. Mishonov (EDs.), Temperature, (Vol. 1, pp. 40-73). NOAA Atlas NESDIS.

Mason, E., Pascual, A., \& McWilliams, J. C. (2014). A new sea surface height-based code for oceanic mesoscale eddy tracking. Journal of Atmospheric and Oceanic Technology, 31(5), 1181-1188. https://doi.org/10.1175/JTECH-D-14-00019.1

Matear, R. J., \& Hirst, A. C. (2003). Long-term changes in dissolved oxygen concentrations in the ocean caused by protracted global warming. Global Biogeochemical Cycles, 17(4), 1125. https://doi.org/10.1029/2002GB001997

McGillicuddy, D. J. (2016). Mechanisms of physical-biological-biogeochemical interaction at the oceanic mesoscale. Annual Review of Marine Science, 8(1), 125-159. https://doi.org/10.1146/annurev-marine-010814-015606

Morales, C. E., Hormazábal, S. E., \& Blanco, J. L. (1999). Interannual variability in the mesoscale distribution of the depth of the upper boundary of the oxygen minimum layer off northern Chile (18-24S): Implications for the pelagic system and biogeochemical cycling. Journal of Marine Research, 57(6), 909-932. https://doi.org/10.1357/002224099321514097

Morales, C. E., Hormazabal, S., Correa-Ramirez, M. A., Pizarro, O., Silva, N., Fernandez, C., et al. (2012). Mesoscale variability and nutrient-phytoplankton distributions off central-southern Chile during the upwelling season: The influence of mesoscale eddies. Progress in Oceanography, 104, 17-29. https://doi.org/10.1016/j.pocean.2012.04.015

Nakata, H., Kimura, S., Okazaki, Y., \& Kasai, A. (2000). Implications of meso-scale eddies caused by frontal disturbances of the Kuroshio Current for anchovy recruitment. ICES Journal of Marine Science, 57(1), 143-152. https://doi.org/10.1006/jmsc.1999.0565

Oerder, V., Colas, F., Echevin, V., Codron, F., Tam, J., \& Belmadani, A. (2015). Peru-Chile upwelling dynamics under climate change. Journal of Geophysical Research: Oceans, 120(2), 1152-1172. https://doi.org/10.1002/2014JC010299

Oschlies, A., Brandt, P., Stramma, L., \& Schmidtko, S. (2018). Drivers and mechanisms of ocean deoxygenation. Nature Geoscience, 11(7), 467-473. https://doi.org/10.1038/s41561-018-0152-2

Paulmier, A., \& Ruiz-Pino, D. (2009). Oxygen minimum zones (OMZs) in the modern ocean. Progress in Oceanography, 80(3-4), 113-128. https://doi.org/10.1016/j.pocean.2008.08.001

Pegliasco, C., Chaigneau, A., \& Morrow, R. (2015). Main eddy vertical structures observed in the four major Eastern Boundary Upwelling Systems. Journal of Geophysical Research: Oceans, 120(9), 6008-6033. https://doi.org/10.1002/2015JC010950

Penven, P., Echevin, V., Pasapera, J., Colas, F., \& Tam, J. (2005). Average circulation, seasonal cycle, and mesoscale dynamics of the Peru Current System: A modeling approach. Journal of Geophysical Research, 110, C10. https://doi.org/10.1029/2005JC002945

Pizarro, O. (2002). Dynamics of seasonal and interannual variability of the Peru-Chile Undercurrent. Geophysical Research Letters, 29(12), 1581. https://doi.org/10.1029/2002GL014790

Pizarro-Koch, M., Pizarro, O., Dewitte, B., Montes, I., Ramos, M., Paulmier, A., \& Garçon, V. (2019). Seasonal variability of the southern tip of the oxygen minimum zone in the eastern South Pacific $\left(30^{\circ}-38^{\circ} \mathrm{S}\right)$ : A modeling study. Journal of Geophysical Research: Oceans, 124(12), 8574-8604. https://doi.org/10.1029/2019JC015201

Prince, E. D., \& Goodyear, C. P. (2006). Hypoxia-based habitat compression of tropical pelagic fishes. Fisheries Oceanography, 15(6), 451464. https://doi.org/10.1111/j.1365-2419.2005.00393.x

Pujol, M. I., Faugère, Y., Taburet, G., Dupuy, S., Pelloquin, C., Ablain, M., \& Picot, N. (2016). DUACS DT2014: the new multi-mission altimeter data set reprocessed over 20 years. Ocean Science, 12(5), 1067-1090. https://doi.org/10.5194/os-12-1067-2016

Ramos, M., Dewitte, B., Pizarro, O., \& Garric, G. (2008). Vertical propagation of extratropical Rossby waves during the 1997-1998 El Niño off the west coast of South America in a medium-resolution OGCM simulation. Journal of Geophysical Research, 113, C8. https://doi. org/10.1029/2007JC004681

Ramos, M., Pizarro, O., Bravo, L., \& Dewitte, B. (2006). Seasonal variability of the permanent thermocline off northern Chile. Geophysical Research Letters, 33, 9. https://doi.org/10.1029/2006GL025882

Schmidtko, S., Stramma, L., \& Visbeck, M. (2017). Decline in global oceanic oxygen content during the past five decades. Nature, 542(7641), 335-339. https://doi.org/10.1038/nature21399

Shaffer, G., Olsen, S. M., \& Pedersen, J. O. P. (2009). Long-term ocean oxygen depletion in response to carbon dioxide emissions from fossil fuels. Nature Geoscience, 2(2), 105-109. https://doi.org/10.1038/ngeo420

Silva, N., \& Neshyba, S. (1979). Masas de agua y circulacion geostrófica frente a la costa de Chile Austral. Serie Cientifica - Instituto Antartico Chileno, 25/26, 5-32.

Silva, N., Rojas, N., \& Fedele, A. (2009). Water masses in the Humboldt Current System: Properties, distribution, and the nitrate deficit as a chemical water mass tracer for Equatorial Subsurface Water off Chile. Deep Sea Research Part II: Topical Studies in Oceanography, 56(16), 1004-1020. https://doi.org/10.1016/j.dsr2.2008.12.013

Stramma, L., Bange, H. W., Czeschel, R., Lorenzo, A., \& Frank, M. (2013). On the role of mesoscale eddies for the biological productivity and biogeochemistry in the eastern Tropical Pacific Ocean off Peru. Biogeosciences, 10(11), 7293-7306. https://doi.org/10.5194/ bg-10-7293-2013

Stramma, L., Johnson, G. C., Firing, E., \& Schmidtko, S. (2010). Eastern Pacific oxygen minimum zones: Supply paths and multidecadal changes. Journal of Geophysical Research, 115, C9. https://doi.org/10.1029/2009JC005976

Stramma, L., Johnson, G. C., Sprintall, J., \& Mohrholz, V. (2008). Expanding oxygen-minimum zones in the tropical oceans. Science, 320(5876), 655-658. https://doi.org/10.1126/science.1153847

Stramma, L., Oschlies, A., \& Schmidtko, S. (2012). Mismatch between observed and modeled trends in dissolved upper-ocean oxygen over the last 50 yr. Biogeosciences, 9(10), 4045-4057. https://doi.org/10.5194/bg-9-4045-2012

Stramma, L., Prince, E. D., Schmidtko, S., Luo, J., Hoolihan, J. P., Visbeck, M., et al. (2011). Expansion of oxygen minimum zones may reduce available habitat for tropical pelagic fishes. Nature Climate Change, 2(1), 33-37. https://doi.org/10.1038/nclimate1304

Stramma, L., Weller, R. A., Czeschel, R., \& Bigorre, S. (2014). Eddies and an extreme water mass anomaly observed in the eastern south Pacific at the Stratus mooring. Journal of Geophysical Research: Oceans, 119(2), 1068-1083. https://doi.org/10.1002/2013JC009470

Swartzman, G., Bertrand, A., Gutiérrez, M., Bertrand, S., \& Vasquez, L. (2008). The relationship of anchovy and sardine to water masses in the Peruvian Humboldt Current System from 1983 to 2005. Progress in Oceanography, 79(2-4), 228-237. https://doi.org/10.1016/j.pocean.2008.10.021

Tew Kai, E., \& Marsac, F. (2010). Influence of mesoscale eddies on spatial structuring of top predators' communities in the Mozambique Channel. Progress in Oceanography, 86(1-2), 214-223. https://doi.org/10.1016/j.pocean.2010.04.010

Thomsen, S., Kanzow, T., Krahmann, G., Greatbatch, R. J., Dengler, M., \& Lavik, G. (2016). The formation of a subsurface anticyclonic eddy in the Peru-Chile Undercurrent and its impact on the near-coastal salinity, oxygen, and nutrient distributions. Journal of Geophysical Research: Oceans, 121(1), 476-501. https://doi.org/10.1002/2015JC010878 
Ulloa, O., Canfield, D. E., DeLong, E. F., Letelier, R. M., \& Stewart, F. J. (2012). Microbial oceanography of anoxic oxygen minimum zones. Proceedings of the National Academy of Sciences, 109(40), 15996-16003. https://doi.org/10.1073/pnas.1205009109

Vega, A., du-Penhoat, Y., Dewitte, B., \& Pizarro, O. (2003). Equatorial forcing of interannual Rossby waves in the eastern South Pacific. Geophysical Research Letters, 30(5), 1197. https://doi.org/10.1029/2002GL015886

Vergara, O., Dewitte, B., Montes, I., Garçon, V., Ramos, M., Paulmier, A., \& Pizarro, O. (2016). Seasonal variability of the oxygen minimum zone off Peru in a high-resolution regional coupled model. Biogeosciences, 13(15), 4389-4410. https://doi.org/10.5194/bg-13-4389-2016

Wishner, K. F., Seibel, B., \& Outram, D. (2020). Ocean deoxygenation and copepods: Coping with oxygen minimum zone variability. Biogeosciences, 17(8), 2315-2339. https://doi.org/10.5194/bg-17-2315-2020

Yamamoto, A., Abe-Ouchi, A., Shigemitsu, M., Oka, A., Takahashi, K., Ohgaito, R., \& Yamanaka, Y. (2015). Global deep ocean oxygenation by enhanced ventilation in the Southern Ocean under long-term global warming. Global Biogeochemical Cycles, 29(10), 1801-1815. https://doi.org/10.1002/2015GB005181

Zweng, M. M, Reagan, J. R., Antonov, J. I., Locarnini, R. A., Mishonov, A. V., Mishonov, T. P., et al. (2013). World Ocean Atlas 2013. In S. Levitus \& A. Mishonov Technical (Eds.), Salinity, (Vol. 2, pp. 39-74). NOAA Atlas NESDIS. 